University of Zurich

Department of Economics

Working Paper Series

ISSN 1664-7041 (print)

ISSN 1664-705X (online)

Working Paper No. 68

\title{
The Incidence of Cash for Clunkers: An Analysis of the 2009 Car Scrappage Scheme in Germany
}

Ashok Kaul, Gregor Pfeifer and Stefan Witte

April 2012 


\title{
The Incidence of Cash for Clunkers
}

An Analysis of the 2009 Car Scrappage Scheme in Germany

\author{
Working Paper
}

Ashok Kaul, Gregor Pfeifer, Stefan Witte *

April 5, 2012

\begin{abstract}
Governments all over the world have invested tens of billions of dollars in car scrappage programs to fuel the economy in 2009. We investigate the German case using a unique micro transaction dataset covering the years 2007 to 2010 . Our focus is on the incidence of the subsidy, i.e., we ask how much of the $€ 2,500$ buyer subsidy is captured by the supply-side through an increase in selling prices. Using regression analysis, we find that average prices in fact decreased for subsidized buyers in comparison to non-subsidized ones, suggesting that eventually subsidized customers benefitted by more than the subsidy amount. However, the incidence was heterogeneous across price segments. Subsidized buyers of cheap cars paid more than comparable buyers who did not receive the subsidy, e.g. for cars of $€ 12,000$ car dealers reaped about $8 \%$ of the scrappage prime. The opposite was true for more expensive cars, e.g. subsidized buyers of cars of $€ 32,000$ were granted an extra discount of about $€ 1,100$. For cars priced about $€ 18,000$, we find no price discrimination, i.e., in this price segment consumers fully captured the transfer. Our results can be explained by optimizing behavior on the supply-side both in the lower and upper price segments. The results are extremely robust to extensive sensitivity checks.
\end{abstract}

Keywords: Cash-for-Clunkers, scrappage scheme, incidence, subsidy, pricing.

JEL Classification Numbers: H22, D12, L62.

*Kaul: Saarland University, Department of Economics, Campus Building C3.1, D-66123 Saarbrücken, Germany and University of Zurich, Department of Economics, Wilfriedstrasse 6, CH-8032 Zurich, Switzerland; Email: ashok.kaul@mx.uni-saarland.de. Pfeifer: Saarland University, Department of Economics, Campus Building C3.1, D-66123 Saarbrücken, Germany; Email: g.pfeifer@mx.uni-saarland.de. Witte: Saarland University, Department of Economics, Campus Building C3.1, D-66123 Saarbrücken, Germany; Email: s.witte@mx.uni-saarland.de. 


\section{Introduction}

As a reaction to the 2007 economic crisis, governments around the world launched car scrappage programs to stimulate the economy. While the U.S. spent $\$ 3$ billion on their "Cash-for-Clunkers" program, Germany afforded the most expensive scheme of all countries with a total volume of about $\$ 7$ billion ( $€ 5$ billion). Most programs took effect in 2009 but they were neither a recent invention nor limited to cars alone. Given their popularity amongst policy makers and consumers (i.e., voters), similar programs are likely to be adopted in the future. A careful evaluation of the incidence of the government intervention is therefore a highly relevant policy question that has not yet been treated in the literature concerned with scrapping schemes.

The German scrappage program, called Abwrackprämie (scrappage prime) or Umweltprämie (environmental prime), started in late January 2009. To receive the lump-sum subsidy of $€ 2,500$ (about $\$ 3,500)$, buyers (private households) had to prove scrappage of an old car and registration of a new one. By September 2009, the budget was exhausted, subsidizing the purchase of 2 million new cars. Car dealers in general managed the scrapping of the old car and dealt with the responsible federal agency. In many cases, they even advanced the money of the subsidy. Thus, car dealers generally knew whether a customer was receiving the subsidy or not. This suggests that there was potential for price discrimination in the buyer-dealer price negotiations. Our market transaction data, in line with national new car registration counts, show that purchases for lower priced segments (like Mini, Small, Medium, and MPV (Multi Purpose Vehicle) ) doubled in 2009 while a stagnation or a decline for more expensive cars can be observed. Car dealers and the media reported that people were queuing up in front of dealerships and dealers were busy writing up sales contracts rather than doing anything else.

Using a unique sample of micro transaction data for Germany over the years 2007 to 2010 , we ask how much of the $€ 2,500$ buyer subsidy is captured by the 
supply-side through an increase in selling prices. To answer this question, we apply linear regression methods and model the (percentage) discount from the manufacturer's suggested retail price (MSRP) as a function of the scrappage dummy, the MSRP, and various controls. Our focus is on the discount received by subsidized buyers in comparison to non-subsidized buyers controlling for covariates. In a fist step, we surprisingly find that the average effect of the prime on discount was slightly positive, implying that customers (on average) captured more than the total amount of the subsidy. We therefore allow for heterogeneity across price segments when comparing subsidized to non-subsidized purchases and find that these differ significantly. Subsidized buyers of the first quartile (cheap cars) received less discount than non-subsidized buyers. Somewhere in the second quartile, the difference was just zero implying just no pass-through of the subsidy to the dealers at all. Above the median MSRP, the discount for subsidized buyers was higher than the discount for non-subsidized ones.

To illustrate the heterogeneity in the incidence of the scrappage subsidy, consider the following examples: For a $€ 12,000$ car purchase, about 1.6 percentage points of the MSRP were skimmed off by car dealers. Regarding the subsidy amount of $€ 2,500$ this implies that dealers captured approximately $8 \%$ of the subsidy. For a $€ 32,000$ car, on the other hand, dealers granted an extra 3.5 percentage points of the MSRP or about $45 \%$ of the subsidy. Put differently, they granted an extra discount of approximately $€ 1,100$ to attract customers receiving the subsidy in comparison to those who did not. For a price of about $€ 18,000$ we observe no pass-through, i.e., customers captured the entire subsidy of $€ 2,500$. The results are extremely robust to all kinds of data restrictions as well as model modifications.

This pattern can be explained by price discrimination depending on market conditions in different market segments. The scrappage program shifted demand heavily towards the lowest price segment (small cars), giving dealers some market power and thus allowing for price making. Additionally, dealers were able to identify two groups with a different price elasticity of demand. The group of 
subsidized buyers was eager to buy a new — and due to the subsidy — very cheap car and therefore tended to be comparatively less price sensitive. In contrast to this, the group of non-subsidized buyers was more price sensitive. Therefore, in this price segment car dealers were able to enforce a price-markup for the subsidized group by granting lower discounts to these buyers as compared to non-subsidized ones. As pricing in these lower segments is very aggressive overall, this markup could not become very big. In the upper price segment (large cars), demand was slack due to the financial crisis and therefore stocks were piling up. Dealers used additional discounts in order to attract the subsidized buyer group who would have otherwise tended to buy a car in a lower price segment (medium cars). In the upper price segment, receiving the subsidy therefore revealed relatively high price elasticity because, contrary to customers in the lower segments, buyers could easily downgrade. Non-subsidized buyers in these segments, on the other hand, are marked by a rather pronounced brand loyalty. For this group, granting additional discounts due to the crisis does not make sense from a dealer's perspective. In fact, rising discounts for this group would put pressure on prices in the long term.

The paper proceeds as follows. Section 2 provides a literature review. Section 3 gives a short overview over the German scrappage program. Section 4 depicts the dataset and develops the main hypothesis. Section 5 describes the empirical model, shows the regression results as well as a graphical depiction of the main specifications. After discussion for which price range the results are relevant, it quantifies the magnitude of price discrimination for this range. Section 6 provides an extensive interpretation and discussion of the results. Sensitivity checks are presented in section 7 . Section 8 concludes.

\section{Literature}

To the best of our knowledge, this is the first analysis evaluating the incidence of a scrappage subsidy even though those programs have been in place since the 
early 90 's. The paper is closely related to the rapidly growing empirical literature on (tax) incidence. Evans et al. (1999), for instance, analyze the incidence of a tobacco tax showing that $100 \%$ of a tax hike is passed onto consumers in the form of higher prices. Hastings and Washington (2010) investigate the incidence of a food subsidy and find that the increase in aggregate demand induced by benefit delivery results in food price increases. Rothstein (2010) evaluates the tax incidence using the EITC and states that a substantial portion of the intended transfer to low income single mothers is captured by employers through reduced wages. Chetty et al. (2009) show that consumers under-react to taxes that are not salient and that the economic incidence of a tax depends on its statutory incidence, and that even policies that induce no change in behavior can create efficiency losses. Friedman (2009) analyzes the incidence of the Medicare Part D subsidy and finds that pharmaceutical firms would receive $36 \%$ of total surplus over the next ten years relative to $56 \%$ for consumers. For an extensive literature review on tax incidence see Kotlikoff and Summers (1987) and Fullerton and Metcalf (2002).

There is also some research regarding incidence within the automobile market, albeit irrespective of the scrappage context. Busse et al. (2006) analyze cash incentives directed at either the dealer or the customer. They show that customer rebates are passed to the buyer to an extent of $70 \%$ to $90 \%$. Dealer rebates - which are mostly unknown to customers - are passed through only to about $30 \%$ to $40 \%$. Sallee (2011) investigates the case of the Toyota Prius, a car that was tax-subsidized for its fuel efficiency. Despite a binding production constraint on the supply side, Sallee finds that the incentives are fully captured by the customers. He suggests that this is due to a long-term pricing policy of the manufacturer. Verboven (2002) analyzes quality-based price discrimination and the implied tax incidence using tax policies toward gasoline and dieses cars in Europe. He states that manufacturers consider a price-discriminating strategy by charging different profit markups on the gasoline and the diesel variants to exploit consumer mileage heterogeneity. On average, about $75 \%$ to $90 \%$ of the 
price differentials between gasoline and diesel cars can be explained by markup differences.

Within the scrappage context, however, most papers either care about sales or environmental aspects. The literature consistently finds that the increases in sales during the program are offset, often completely, by a decrease in sales in the months after. For instance, Adda and Cooper (2000) and Licandro and Sampayo (2006) examine a French and a Spanish program from the late 90's respectively, while Mian and Sufi (2010) and Li et al. (2010) estimate the impact of CARS in the U.S. Hahn (1995), Deysher and Pickrell (1997), Kavalec and Setiawan (1997), and Szwarcfiter et al. (2005) estimate cost-effectiveness ratios ranging widely from $\$ 2,000-\$ 85,000$ per ton of emissions reductions. Knittel (2009) shows that CARS paid 4 to 10 times more per car than the social benefit of the resulting $\mathrm{CO} 2$ reductions would justify and therefore that there is great potential to waste public funds with that kind of policy interventions. ${ }^{1}$

Our paper contributes to the literature in filling the gap of evaluating and quantifying the incidence of car scrappage subsidies by analyzing the probably most important program launched as a reaction to the recent economic crisis. We develop a simple estimation strategy which can easily be applied to similar programs in other countries.

\section{Program description}

As a reaction to the economic downturn starting in 2007, governments all over the world provided incentives for car replacement. This kind of consumption subsidy is supposed to have three major benefits: (1) It is environmental-friendly by replacing old fuel-consuming cars by new ones with better emission standards. $^{2}$ (2) It helps the automotive manufacturing industry which plays a particularly important role in Germany and involves many stakeholders (the then

\footnotetext{
${ }^{1}$ There is also some theoretical literature regarding scrappage programs, including Moretto (2000), Esteban and Shum (2007), Esteban (2007), and Mazumder and Wu (2008).

2 The German program was actually named environmental prime by the government and it required the new car to fulfill at least the emission standard Euro 4.
} 
vice-chancellor called it the "backbone of our economy"). Problems in this sector would not only come along with the risk of actual layoffs and the corresponding negative spill-overs but also harm consumer confidence severely. (3) It induces consumers to spend a multiple of the voucher's value and can thereby create a multiplier effect in the economy.

The idea for a scrappage program in Germany was picked up by the German vice-chancellor Steinmeier in an interview on December 27, 2008. Only two weeks later, the Government passed an economic stimulus package including a scrappage program. The program officially started on January 14, 2009 and first key points were published on January 16, 2009 by the responsible agency BAFA $^{3}$. The subsidy of $€ 2,500$ could be requested by private individuals who scrapped an old car which was by the time of scrappage at least nine years old and which had been licensed to the applicant for at least 12 months prior to the application. The new car had to be a passenger car fulfilling at least the emission standard Euro 4 and be licensed to the applicant. New cars were defined as those who were licensed for the first time or as annual cars, i.e., had been licensed to a manufacturer or employee of the manufacturer for a maximum of 12 months (14 months after July 2). The regulation thus made sure only private individuals would benefit from the subsidy and there were no gains from buying and scrapping a used car. The money was transferred to the respective buyer after scrappage of the old and registration of the new car were proved. In general, car dealers organized the scrappage and dealt with the federal agency. Many advanced the amount of the subsidy, taking it as a down-payment.

The program turned out to be very popular and the original budget risked to be used up in April. The government raised the budget amount to $€ 5$ billion, ${ }^{4}$ just a few days after switching from a paper-based to an online application

${ }^{3}$ Bundesamt für Wirtschaft und Ausfuhrkontrolle (Federal Office of Economics and Export Control).

${ }^{4}$ To the best of our knowledge, this is the biggest budget provided for scrapping schemes in the world. For an overview see http://www.acea.be/images/uploads/files/20100212_Fleet_Renewal_Schemes_2009.pdf, last accessed on December 20, 2011. 
scheme. By September 2, 2009, the budget was exhausted, subsidizing the purchase of 2 million new cars. The BAFA opened a waiting list of up to 15,000 slots in case of invalid applications. By the end of 2009 the bulk of the requests had been treated by the agency. National new car registration counts show that registrations for lower priced segments (Mini, Small, Medium, and MPV) roughly doubled in 2009 .

\section{Data and Descriptive Evidence}

We analyze a unique set of micro transaction data with 8,156 observations. The data covers information from six randomly chosen car dealers in Germany over six different brands providing information on the purchase of new cars over a time frame of four years (2007-2010). One of those dealers covers two distinct brands and one brand is represented by two different dealers. This helps to avoid the risk of dealer- or brand-specific biases. Because of data privacy reasons we never report the name of a respective dealership or brand. Table 7 in the appendix gives a summary of the distribution.

The data covers detailed information on the car (brand, vehicle class, model) and on the transaction, i.e., the MSRP (manufacturer's suggested retail price, or catalog price), the actual selling price, and hence the granted discount. It also includes dealer specifics like the corresponding seller as well as buyer specifics like age and sex. Most important, we have information on whether a car was purchased with $(\mathrm{CC})$ or without a Cash-for-Clunkers subsidy (non-CC) within the year $2009 .^{5}$

The distinction CC vs. non-CC is made throughout the year 2009. As described in section 3, the budget was exhausted in early September 2009, but due to the waiting list it was possible to find car purchases marked with a CC indi-

\footnotetext{
${ }^{5}$ Other than new cars it was also possible to purchase annual cars with the subsidy. This category is not considered here since new and annual cars show a very different discount scheme. Moreover, more than $80 \%$ of all subsidy-purchases was on account of new car sales. Annual cars are also excluded from the analysis because there is no reliable information on their actual value which would correspond to the MSRP.
} 
Table 1: Number of Purchases over Time by Car Dealers and CC

\begin{tabular}{lrrrrr}
\hline & \multicolumn{5}{c}{ Year of Purchase and Clunker's Prime } \\
Car Dealer & $\mathbf{2 0 0 7}$ & $\mathbf{2 0 0 8}$ & $\mathbf{2 0 0 9}$ & $\mathbf{2 0 0 9}$ & $\mathbf{2 0 1 0}$ \\
\hline Dealer 1 & & & Non-CC & CC & \\
Dealer 2 & 315 & 443 & 587 & 317 & 504 \\
Dealer 3 & 250 & 235 & 268 & 330 & 381 \\
Dealer 4 & 263 & 314 & 277 & 359 & 286 \\
Dealer 5 & 633 & 484 & 346 & 135 & 270 \\
Dealer 6 & 81 & 67 & 60 & 43 & 43 \\
Total & 12 & 158 & 111 & 357 & 227 \\
\hline
\end{tabular}

cator within our dataset from January 2009 until December 2009 which makes the entire year 2009 our scrappage period. Moreover, the CC purchases are concentrated in the months February to October and then fade out (see Table 8 in the appendix). ${ }^{6}$

Table 1 shows how the number of purchases is distributed over time within our sample. Sales doubled due to the CC prime and this pattern can be found for almost every single dealership included.

Table 2 provides a summary of essential variables of the overall dataset. The average car cost about $€ 25,600$ and earned approximately $17 \%$ discount. Roughly $30 \%$ of all buyers are female. About $16 \%$ of all purchases refer to demonstration cars and $12 \%$ refer to sales to employees of auto manufacturers (called "company employees" subsequently). The average buyers age was 47 years but we only observe 1,425 (out of 8,156 ) data points featuring customer age information. The remarkably high percentage discount over $50 \%$ (max) was due to the fact that demonstration cars as well as company employees benefit from huge (and) additional discounts. ${ }^{7}$

Figure 1 shows the number of observed purchases for the different vehicle classes over the observation period. ${ }^{8}$ Mainly cheap vehicle classes like A (Mini),

\footnotetext{
${ }^{6}$ This is in line with the distribution of applications for the subsidy as reported by the BAFA. ${ }^{7}$ The high discount of more than $€ 50,000$ was observed for a demonstration car of the most expensive category (luxury car segment).

${ }^{8}$ The classification A, B, C, D, E, F, J, M, S is in accordance to the EU-classification. For an overview see http://ec.europa.eu/competition/mergers/cases/decisions/m1406_en.pdf,
} 
Table 2: Summary Statistics: All Data

\begin{tabular}{lrrrrrr}
\hline Variables & Mean & SD & Med & Min & Max & N \\
\hline Discount in Percent & 16.91 & 8.68 & 16.40 & 0.00 & 53.37 & 8,156 \\
Discount in 1000 EUR & 4.18 & 3.23 & 3.44 & 0.00 & 51.81 & 8,156 \\
MSRP in 1000 EUR & 25.62 & 14.37 & 21.50 & 8.19 & 198.66 & 8,156 \\
Clunker's Prime (CC) & 0.19 & 0.39 & 0 & 0 & 1 & 8,156 \\
Demonstration Car (DC) & 0.16 & 0.37 & 0 & 0 & 1 & 8,156 \\
Company Employee (CE) & 0.12 & 0.32 & 0 & 0 & 1 & 8,156 \\
Female & 0.29 & 0.45 & 0 & 0 & 1 & 8,156 \\
Age at Purchase & 47.23 & 14.93 & 48 & 18 & 89 & 1,425 \\
\hline
\end{tabular}

Note: MSRP is the manufacturer suggested retail price. DC is a dummy variable indicating whether a buyer bought a demonstration car $(D C=1)$. CE is a dummy variable indicating whether the buyer was an employee of a car manufacturing company $(C E=1)$. $C C$ is a dummy variable indicating whether the buyer of a car received the scrappage subsidy $(C C=1)$. Female is a dummy of female buyers, the summary statistics therefore report the share of women.

B (Small), C (Medium), and M (MPV) benefited from the program. Note that there is no evidence for a severe dip in 2010. We rather observe a trend towards some vehicle classes like B (Small) or J (Sport Utility Vehicle or SUV) to the detriment of medium and large cars $(\mathrm{C}$ and $\mathrm{D})$ as well as sports coupés $(\mathrm{S})$. Overall, it seems that the subsidized acquisitions did happen over and above the regular purchases and were not pulled forward from the following purchase period. We do not find many additional purchases in vehicle classes D (Large), E (Executive), F (Luxury), and S ( Sports Coupés). ${ }^{9}$

Figure 2 shows the development of the discount over time per vehicle class. As mentioned above, inexpensive vehicle classes experienced an increase in car purchases while the more pricey segments faced a staggering or declining demand. One can see that some of the segments which experienced a positive demand shock (Mini and Small) are the ones which get less discount throughout 2009 when purchased as CC car compared to non-CC cars. For the other, more expensive segments, the opposite happens: CC customers received comparatively more discount. ${ }^{10}$

\footnotetext{
last accessed on January 26, 2012.

${ }^{9}$ This is not surprising since expensive cars are predominantly purchased by corporate customers, so they obviously played a minor role within the scrapping context.

${ }^{10}$ Summary statistics for the MSRP over vehicle classes are given in Table 10 in the appendix. It shows that prices rise monotonically over the vehicle classes A through to F. The mean price of MPVs is similar to Medium Cars; SUVs cost on average as much as Large Cars; Sports Coupés are comparable to Executive Cars. The standard deviation of the prices
} 


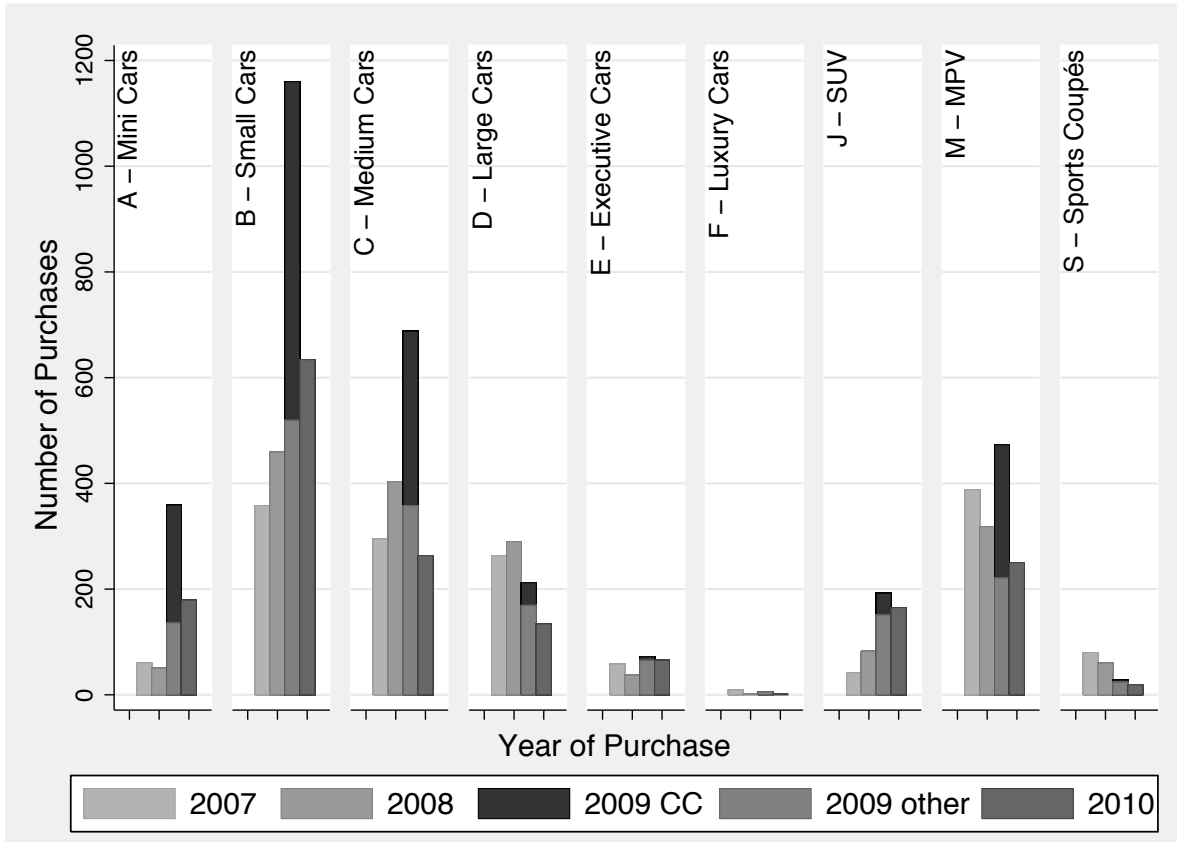

Note: A, B, C, D, E, F, J, M, S are auto segments according to the EU-car classification. $C C$ is a dummy variable indicating whether the buyer of a car received the scrappage subsidy $(C C=1)$. 2009 CC are car purchases in 2009 involving the scrappage subsidy, 2009 others are non-subsidized purchases. $S U V$ stands for Sport Utility Vehicle, $M P V$ for Multi Purpose Vehicle

Figure 1: Number of Purchases over Time by EU-Vehicle Class 


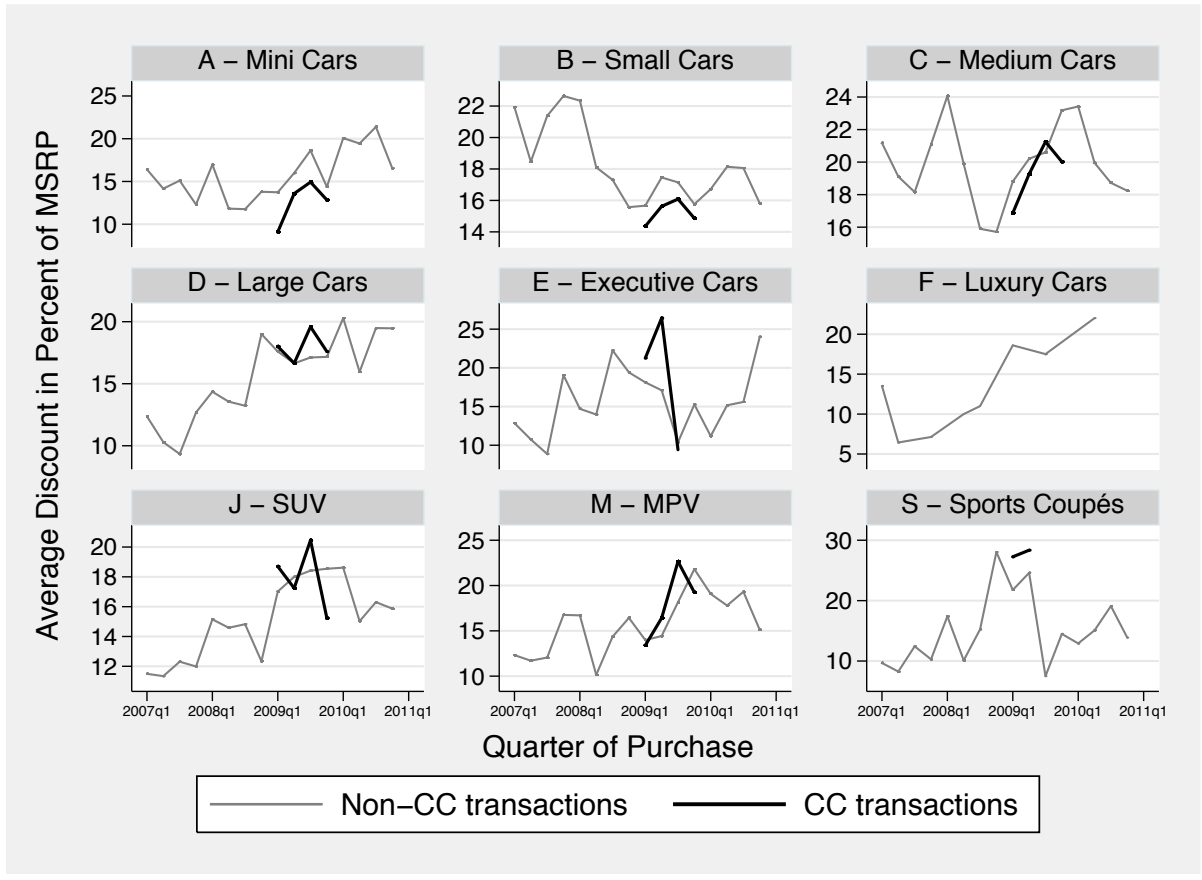

Note: $S U V$ stands for Sport Utility Vehicle, $M P V$ for Multi Purpose Vehicle.

Figure 2: Percentage Discount over Time by EU-Vehicle Class

The same pattern arises within vehicle classes (see Figure 5 in the appendix), namely that subsidized cars are cheaper than non-subsidized ones. We therefore control for MSRP in our regression model rather than interactions of "make, model, and turn" as it was possible for Busse et al. (2006). More important, using MSRP allows to control for differences in optional equipment since any additional feature is included in the catalog price.

In a next step, we deepen this discussion a little further by moving from a rather graphical to a more numerical focus and present essential figures. First, we take a closer look at 2009 (Table 9 in the appendix gives summary statistics for that year only). Due to the demand shock induced by the subsidy we have to expect repercussions on the entire market. The average MSRP in 2009 was about $€ 2,500$ lower compared to the overall mean due to a difference in composition: more small and smallest cars were bought in that period. The av-

of the last three categories are about twice as big as the one of their respective reference category. The last three vehicle classes are therefore consistent with the described pattern. 
erage discount in $2009(17.7 \%)$ is relatively stable when compared to the overall discount (16.9\%). About $14 \%$ and $13 \%$ of the 2009 purchases refer to demonstration cars and company employees respectively. Table 3 shows the difference for relevant variables between subsidized and non-subsidized purchases within year 2009. It highlights that there is a difference in discount in percent and Euro between the subsidized and non-subsidized cars which buttresses the assumption of a dealer induced price discrimination. Non-CC cars got a discount of $17.67 \%$ whereas CC cars received $16.51 \% .{ }^{11}$ The corresponding absolute values are $€ 4,686$ and $€ 3,235$ respectively. These differences are significant at the $1 \%$ level. Yet, this should not lead to a hasty conclusion because we obviously have to take the MSRP into consideration: Non-CC cars on average cost $€ 26,720$ whereas CC cars amounted to about $€ 19,062 .{ }^{12}$ This means that customers who called upon the subsidy on average asked for smaller (cheaper) cars than customers who purchased without the subsidy denoting differences in the group compositions of $\mathrm{CC}$ and non-CC customers. We will thus have to control for MSRP in our regression analysis rather than for vehicle class. Furthermore, there are about $25 \%$ women within the non-CC group and about $39 \%$ within the CC group. The shares of demonstration cars and company employees are 19\% vs. $10 \%$ and $17 \%$ vs. $8 \%$ (non-CC vs. CC) respectively. The last information is important because the unequal share of the two high-discount categories might be driving the difference in percentage discount. Both categories make up for a smaller share in the CC group compared to the reference group which implies that the average discount of $\mathrm{CC}$ purchases would rather be biased downward and with it the reported difference in percentage discount. ${ }^{13}$ In the following analysis, we therefore have to control for both groups.

\footnotetext{
${ }^{11}$ Table 11 in the appendix gives an overview of the percentage discount's development over the years including a $\mathrm{CC} /$ non-CC distinction.

${ }^{12}$ The distribution of the MSRP of subsidized cars is concentrated among lower prices. Its median is $€ 17,000$ and the 75 th percentile is at about $€ 22,000$.

${ }^{13}$ Table 12 in the appendix shows the percentage discount by different so called types of purchases (company employees, demonstration cars or any other purchase - called standard). While company employees and demonstration cars receive average discounts of about $26 \%$ and $23 \%$ respectively, a normal customer (no company employee) who did purchase a normal car (no demonstration car) receives on average a discount of $14 \%$.
} 
Table 3: Summary Statistics: Comparison within 2009 by CC

\begin{tabular}{lrrrrr}
\hline \multirow{2}{*}{ Variables } & \multicolumn{2}{c}{ Non-CC } & \multicolumn{2}{c}{ CC } & Diff \\
& Mean & SD & Mean & SD & Mean \\
\hline Discount in Percent & 17.67 & 8.73 & 16.51 & 6.67 & -1.16 \\
Discount in 1000 EUR & 4.69 & 3.80 & 3.24 & 2.15 & -1.45 \\
MSRP in 1000 EUR & 26.72 & 15.27 & 19.06 & 7.56 & -7.66 \\
Demonstration Car (DC) & 0.19 & 0.39 & 0.10 & 0.29 & -0.09 \\
Company Employee (CE) & 0.17 & 0.38 & 0.08 & 0.28 & -0.09 \\
Female & 0.25 & 0.43 & 0.39 & 0.49 & 0.14 \\
Age at Purchase & 44.84 & 14.92 & 48.19 & 15.08 & 3.35 \\
\hline
\end{tabular}

Note: Non-CC are non-subsidized purchases, CC subsidized ones. The last column gives the difference between CC and non-CC purchases. MSRP is the manufacturer suggested retail price. DC is a dummy variable indicating whether a buyer bought a demonstration car $(D C=1)$. CE is a dummy variable indicating whether the buyer was an employee of a car manufacturing company $(C E=1)$ Female is a dummy of female buyers, the summary statistics therefore report the share of women.

Both the descriptive and the graphical evidence suggest that price discrimination across consumers of different market segments as well as price discrimination between subsidized and non-subsidized buyers may have been present. A closer look reveals that this probably depends on the vehicle class: subsidized customers who bought (very) small up to medium cars received less discount compared to non-subsidized customers; when purchasing bigger cars the opposite seems to be true, namely that subsidized buyers received more discount than non-subsidized ones. Yet, we need to control for various aspects like the exact MSRP, the year of purchase, the kind of dealer and brand, as well as high discount groups.

\section{$5 \quad$ Model and Results}

We wish to estimate the effect on consumers of receiving the scrappage prime, a buyer subsidy, for their car purchases in comparison to otherwise comparable non-subsidized buyers. As we saw in section 4, the effect is heterogeneous across price segments. We first present a basic specification to estimate the average weighted impact from which we develop an augmented specification which takes account of the heterogeneity. This full specification models the discount of 
MSRP as a function of the scrappage-dummy interacted with MSRP as well as the MSRP itself. We show graphically that this specification is not sensitive to a more flexible estimation approach. Taking into account the distribution of purchases and the share of subsidized purchases over the price range, we show for which interval of MSRP our results are relevant. To illustrate the estimated differences, we show the magnitude of price discrimination in percentage points and Euros over what we consider the relevant price range.

\subsection{Basic Specification}

In our most basic specification, we estimate the following regression model:

$$
\text { discount }=\alpha+\beta \cdot C C+\gamma \cdot M S R P+\theta^{\prime} \cdot X+\epsilon
$$

The dependent variable (discount) is the discount in percent of the MSRP the household received for a single car purchase. The key explanatory variable of interest is $C C$, namely the Cash-for-Clunkers dummy variable, i.e., an indicator whether a car was purchased with the scrappage subsidy $(C C=1)$ or without it $(C C=0)$. MSRP denotes the manufacturer's suggested retail price or catalog price (in $€ 1,000$ ). It is an important control variable that allows to take dealers' discount policy in different market segments into account. The vector $X$ contains a set of other controls. Brands and dealers are modeled as seven brand-dealer dummies, i.e., there is a dummy for each combination of brand and dealer. Dummies for buyers who are employees of car manufacturing companies ("company employees", $C E$ ) and demonstration cars $(D C)$ are included. Also a dummy for each individual seller is included as well as a sex dummy for buyers and year and month dummies to capture seasonalities and macroeconomic effects are included. The error term is represented by $\epsilon$.

The estimated coefficients are $\alpha, \beta, \gamma$ and the vector $\theta$. The key coefficient of interest in this specification is $\beta$. It measures the percentage difference in discount a subsidized buyer received in comparison to an non-subsidized buyer. 
A positive (negative) estimate of $\beta$ indicates that subsidized buyers received a higher (lower) discount than non-subsidized buyers, controlling for the covariates mentioned above. The coefficient $\gamma$ measures how dealers' discount policy differs across price segments. To be precise, $\gamma$ measures how the discount changes due to an increase of $€ 1,000$ in MSRP, holding other things constant.

Column (1) of Table 4 reports the results of estimating the specification in equation (1). The estimated coefficient $\beta$ measuring the effect of receiving the scrappage subsidy on the discount granted for a car purchase is 0.4 . It is positive and statistically different from zero at the $10 \%$-level. This suggests that the overall pass-through of the subsidy was negative, i.e., dealers grant a 0.4 percentage points bigger discount for CC purchases than for non-subsidized ones, controlling for the discussed covariates. Although the coefficient is quantitatively small (compared to a mean value of about $17 \%$, see section 4 ), the result is surprising since a capturing of a subsidy of more than $100 \%$ is not consistent with the related empirical literature. ${ }^{14}$ The value of 0.05 for $\gamma$ suggests that the percentage discounts grows at a rate of about 0.05 percentage points with every $€ 1,000$ of MSRP. This means that a difference of $€ 20,000$ implies a one percentage point higher discount. Before discussing the controls in vector $\theta$, consider the full model which takes into account that the effect is heterogeneous over the price range.

\section{$5.2 \quad$ Full Specification}

Specification (1) has a shortcoming, namely that it restricts the effect of receiving the subsidy on the discount to be uniform across price segments. However, as discussed in section 4 , market conditions and discounts itself were different over price segments. Therefore, we have reasons to expect the effect of the prime to be heterogeneous over the whole price range.

To account for such a heterogeneous effect, we interact the dummy $C C$ with

\footnotetext{
${ }^{14}$ Busse et al. (2006) find a pass-through of 70\%-90\%, Sallee (2011) a full pass-through. Note that these articles define pass-through as the share of the cash-incentive amount that remains with the customer.
} 
the catalog price MSRP $(C C * M S R P)$ and estimate the regression model in equation (2). ${ }^{15}$ We thereby allow for differences between regular and subsidized purchases varying over the MSRP. Results are presented in specification (2) of Table 4.

$$
\text { discount }=\alpha+\beta \cdot C C+\gamma \cdot M S R P+\delta \cdot C C * M S R P+\theta^{\prime} \cdot X+\epsilon
$$

Estimating this specification, all the essential coefficients- $\beta, \gamma$, and $\delta$-are statistically significantly different from zero at the $1 \%$ level. The results confirm our expectations: controlling for individual- and dealer-specifics as well as time trends and high-discount groups $(D C$ and $C E)$, we find a strong relationship between the MSRP, the subsidy and the discount in percent. We see that $\beta$, the coefficient for $\mathrm{CC}$, is negative, with -4.4 rather big, ${ }^{16}$ and highly significant. The estimate for $\delta$ is 0.24 and hence positive, implying that the more expensive a car was, the more additional discount was granted if the buyer benefited from the subsidy. The coefficient of $\operatorname{MSRP}(\gamma)$ is 0.03 and thus a little smaller than in specification (1) but qualitatively not different.

Note that throughout the different specifications, the controls in vector $\theta$ remain stable: The coefficients of the controls for company employees $(C E)$ and demonstration car $(D C)$ hardly change. While the coefficient of $D C$ is about 11, the one for $C E$ is about 11.5. Consumers who bought a demonstration car received a plus of about 11 percentage points of discount compared to buyers of non-demonstration (standard) cars. For company employees it is a plus of about 10.5 percentage points. Both coefficients are always significant at the $1 \%$ level. These percentage values experienced some downward adjustment compared to the descriptive analysis (see section 4) but are still impressively different (lower) compared to a normal consumer who bought a normal car, i.e.,

\footnotetext{
${ }^{15}$ As discussed previously, we cannot simply interact $C C$ with a set of vehicle class dummies because within each such class, the two groups (subsidized and non-subsidized purchases) differ.

${ }^{16}$ Note that the dummy itself has no meaningful interpretation as it measures the difference to the overall constant for a price of zero. Interpreting this value as such would be an inadmissible extrapolation.
} 
when the purchase involved neither a company employee nor a demonstration car.

The year dummies display the difference in the discount level as compared to the base year 2007. They are, across all specifications, about -0.6 for 2008 , -1.1 for 2009 and -0.4 for 2010 . Discounts thus have been smaller over all three years of observation and they have been smallest in 2009. Yet, this difference is rather small.

Due to the interaction terms, the interpretation of the results is facilitated if we do not discuss single coefficients but the expected percentage discount as a (linear) function of the MSRP. For the group of non-subsidized buyers $(C C=0)$, this function has a y-intersect $(M S R P=0)$ at the constant of 18.05 and a slope coefficient equal to $0.0335 .{ }^{17}$ For the group of subsidized buyers $(C C=1)$, the function has a y-intercept of $18.05-4.401=13.65$ and a slope coefficient equal to $0.2440+0.0335=0.2775$. The latter line is therefore steeper than the former but starts lower. Thus, the two functions intersect at

$$
I_{\text {lin }}=-\beta / \delta
$$

where $\beta$ measures the downward shift of the CC curve for MSRP zero and $\delta$ the difference between the slope of the $\mathrm{CC}$ and the non-CC function. Equation 3 therefore gives the MSRP where both functions intersect. This value is reported at the bottom of Table 4 (Intersect), it is about $€ 18,000$ for specification (2).

\subsection{Flexible Estimation}

In column (3) of Table 4, we test a more flexible specification by augmenting the full model to a quadratic one where we include the square of the MSRP and the square of the interaction term, $(C C * M S R P)^{2}$. Specification (3) shows that the central coefficients like the MSRP, its square, the CC dummy, and the

\footnotetext{
${ }^{17}$ More precisely, the y-intersect depends on the constant as well as the coefficients of any (binary) control variable. To focus on the relevant part of the function and since consideration of these additional controls does not alter the results, we neglect this point in the discussion.
} 
Table 4: Linear Regression Estimation Results of different specifications

All transactions

Dependent variable: Discount in Percent of MSRP

\begin{tabular}{|c|c|c|c|}
\hline VARIABLES & (1) & $(2)$ & (3) \\
\hline $\mathrm{CC}$ & $\begin{array}{l}0.398^{*} \\
(0.233)\end{array}$ & $\begin{array}{c}-4.401^{* * *} \\
(0.503)\end{array}$ & $\begin{array}{c}-6.8527^{* * *} \\
(1.3219)\end{array}$ \\
\hline CC*MSRP & & $\begin{array}{c}0.244^{* * *} \\
(0.0228)\end{array}$ & $\begin{array}{c}0.4881^{* * *} * \\
(0.1220)\end{array}$ \\
\hline$\left(\mathrm{CC}^{*} \mathrm{MSRP}\right)^{2}$ & & & $\begin{array}{c}-0.0050^{*} \\
(0.0026)\end{array}$ \\
\hline MSRP & $\begin{array}{c}0.0453^{* * *} \\
(0.00818)\end{array}$ & $\begin{array}{c}0.0335^{* * *} \\
(0.00800)\end{array}$ & $\begin{array}{c}0.0871 * * * \\
(0.0172)\end{array}$ \\
\hline $\mathrm{MSRP}^{2}$ & & & $\begin{array}{c}-0.0005^{* * *} \\
(0.0002)\end{array}$ \\
\hline DC & $\begin{array}{c}11.01^{* * *} \\
(0.277)\end{array}$ & $\begin{array}{c}10.88^{* * *} \\
(0.276)\end{array}$ & $\begin{array}{c}10.8575^{* * *} \\
(0.2747)\end{array}$ \\
\hline $\mathrm{CE}$ & $\begin{array}{c}11.50^{* * *} \\
(0.313)\end{array}$ & $\begin{array}{c}11.56^{* * * *} \\
(0.312)\end{array}$ & $\begin{array}{c}11.5432^{\text {*** }} \\
(0.3134)\end{array}$ \\
\hline Year $=2008$ & $\begin{array}{c}-0.615^{* * *} \\
(0.230)\end{array}$ & $\begin{array}{c}-0.631^{* * *} \\
(0.229)\end{array}$ & $\begin{array}{c}-0.6542^{* * *} \\
(0.2298)\end{array}$ \\
\hline Year $=2009$ & $\begin{array}{c}-1.108^{* * *} \\
(0.242)\end{array}$ & $\begin{array}{c}-1.137^{* * *} \\
(0.242)\end{array}$ & $\begin{array}{c}-1.1368^{* * *} \\
(0.2416)\end{array}$ \\
\hline Year $=2010$ & $\begin{array}{l}-0.357 \\
(0.243)\end{array}$ & $\begin{array}{c}-0.420^{*} \\
(0.242)\end{array}$ & $\begin{array}{l}-0.3975 \\
(0.2424)\end{array}$ \\
\hline Constant & $\begin{array}{c}17.69^{* * * *} \\
(1.670)\end{array}$ & $\begin{array}{c}18.05^{* * *} \\
(1.673)\end{array}$ & $\begin{array}{c}17.0790^{* * *} \\
(1.6940)\end{array}$ \\
\hline Observations & 8,156 & 8,156 & 8,156 \\
\hline Adjusted R-squared & 0.488 & 0.496 & 0.4976 \\
\hline Month dummies & Yes & Yes & Yes \\
\hline Sex dummy & Yes & Yes & Yes \\
\hline Seller dummies & Yes & Yes & Yes \\
\hline Dealer dummies & Yes & Yes & Yes \\
\hline Intersect & $\mathrm{n} / \mathrm{a}$ & 18.06 & 17.03 \\
\hline
\end{tabular}

Note: *** significant at the $1 \%$-level, ** significant at the $5 \%$-level, $*$ significant at the $10 \%-$ level. Robust standard errors (HC3) in parentheses. CC: dummy for subsidized (Cash-for-Clunkers) transaction, MSRP: Manufacturer's suggested retail price in $€ 1000$, DC: dummy for demonstration car, CE: dummy for employees of auto manufacturing companies. Year $=2008$ (2009) (2010) are dummy variables for the given years, 2007 is the base year. Intersect indicates where the estimated function for subsidized purchases is equal to the baseline function. 
linear interaction term are highly significant ( $1 \%$ level); merely the quadratic interaction term shows a little weaker significance level of $10 \%$. While it is easy to tell from the table that the pattern or the intersect ${ }^{18}$ remains the same over the different specifications, we need to compare the functions estimated in models (2) and (3) to see if they differ significantly within the relevant price range.

We therefore plot the two models in Figure 3 based on the estimated coefficients. We first plot the reference line, i.e., the discount in percent as a function of MSRP for the three models. These are the lower dashed functions in the graph and one can see that they hardly differ. The upper functions are the respective subsidized purchases where one can detect a little more differences between the two models. The dashed vertical lines show the borders of the first, the second and the third quartile of MSRP in 2009. The two functions diverge only from a price of roughly $€ 40,000$ on and are very close to each other even for rather low prices of about $€ 10,000$. The divergence in the upper part is of little importance as the scrappage prime did not play an important role in these price ranges. ${ }^{19}$

The vertical solid lines show the intersects between the $\mathrm{CC}$ and non-CC functions, i.e., the point where there is no difference in discount between a purchase with and without the subsidy. One can see that the intersect is in both cases located within the second quartile. ${ }^{20}$

A general conclusion is that subsidized buyers of the first quartile faced negative price discrimination, i.e., they paid more (experienced a lower discount) if they received the subsidy. In contrast, subsidized buyers in the third (and fourth) quartile faced positive price discrimination, meaning they had to pay

\footnotetext{
${ }^{18}$ For the quadratic model, the intersect is calculated by solving the quadratic equation. We calculated the intersect where the CC curve is steeper than the non-CC curve, i.e., the intersect below the maximum.

${ }^{19}$ There are two major reasons for this: First, the relative importance of the lump-sum subsidy decreases when the car gets more expensive. Second, as the subsidy could only be requested when an old car was scrapped, the old car needed to be of a very low resale value. In general, buyers of expensive cars benefited much more from trading in their old car than scrapping it for $€ 2,500$.

${ }^{20} \mathrm{~A}$ cubic specification (available upon request) would not change this result.
} 


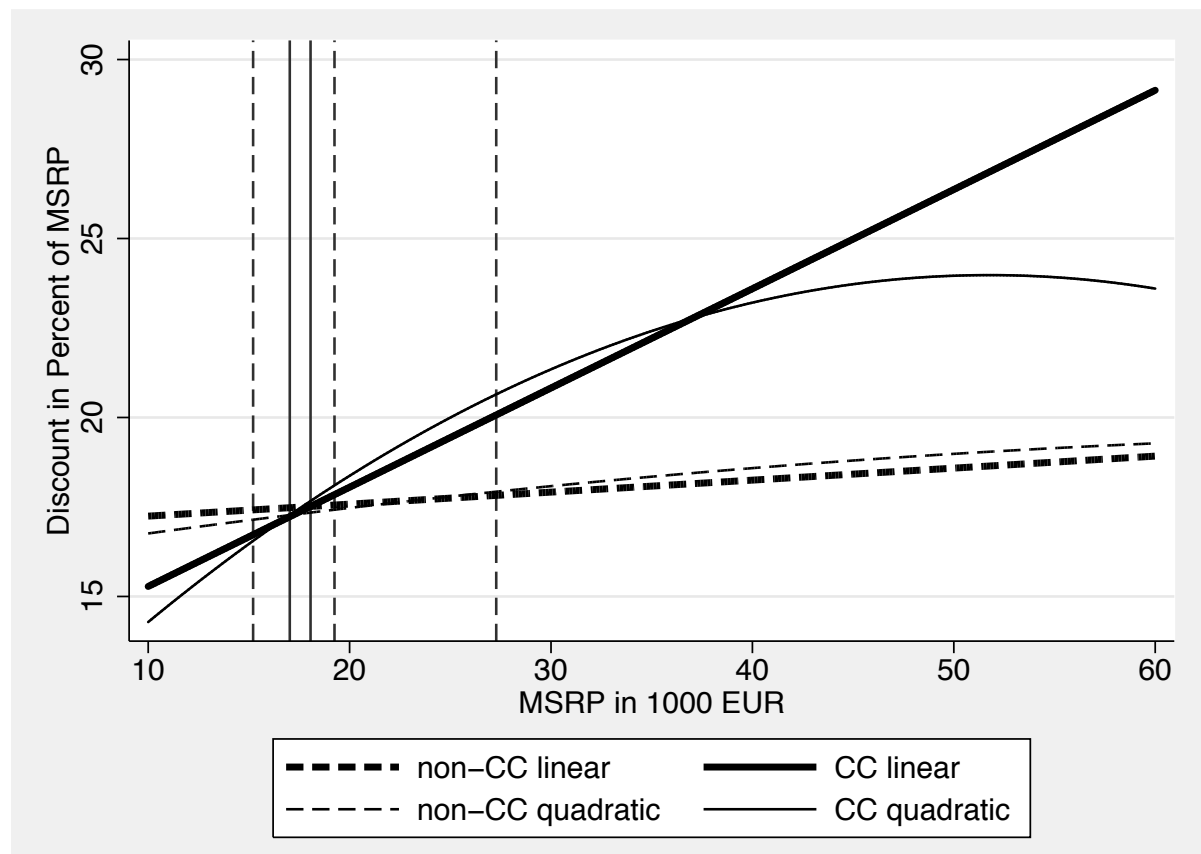

Note: Expected discount in percent as a function of MSRP. Functions are given over two models (linear and quadratic) and two groups, subsidized (CC) and non-subsidized (non-CC) transactions. Parameters are taken from the regression results above, specifications (2) and (3). Graphs are presented for year 2009 only.

Figure 3: Linear and Quadratic Model for Year 2009

less (received more discount) if buying with the subsidy. The positive price discrimination effect in the upper part of the distribution overcompensates the negative effect in the lower part. The reported CC coefficient $\beta$ from specification (1) of Table 4 therefore needs to be interpreted as a weighted average rather than a level effect. Within the second quartile, finally, the difference between the $\mathrm{CC}$ and the non-CC function was just zero. This implies that within the second quartile of MSRP, car dealers did not price discriminate at all and that CC customers therefore received the full amount of the subsidy or $€ 2,500$.

\subsection{The Relevant Price Range}

But how relevant is the region we are considering and are subsidized and nonsubsidized purchases balanced (meaning whether the shares of CC and non-CC purchases are rather equal and therefore comparable)? If this was not the case, 
our results might be misleading. Figure 3 showed that the models do not differ within the most relevant quartiles. Figure 4 now gives some more insight into the distribution and adds the share of CC purchases by MSRP. ${ }^{21}$ The dashdotted line shows the CC share as a falling function of MSRP. This is what we expected, given that the lump-sum subsidy matters relatively more for cheaper cars. However, in a region below $€ 12,000$, the share is larger than $60 \%$, reaching up to $80 \%$ for cars of an MSRP of about $€ 9,000$. We claim that this part of the distribution lacks common support because its composition is so unbalanced. The graph of the distribution (dotted density plot) is very steep on the left side which means that there are relatively few purchases at a price range of about $€ 8,000$ but already many at a price of $€ 10,000$ to $€ 12,000$. Cutting off this fringe, we see that from a MSRP of $€ 12,000$ on the data points are comfortably dense enough and the distribution between $\mathrm{CC}$ and non-CC purchases is rather balanced with about $60 \%$ or less. We learned from Figure 3 that the three models diverge from an MSRP of $€ 40,000$ on. Yet, the share of CC purchases drops below one third at a price of about $€ 32,000$. We choose this point as an upper bound for the following discussion. At this point, we still observe a sufficiently balanced distribution between $\mathrm{CC}$ and non-CC purchases which then steadily shrinks along with the density. This means that the range where our linear model differs from the quadratic one is also a region of low common support plus a region of low density. ${ }^{22}$ In the following discussion, we therefore focus on a price range from $€ 12,000$ to $€ 32,000$ which we judge as the most relevant interval of our data with a solid balance of $\mathrm{CC}$ and non-CC purchases.

\subsection{Price Discrimination}

As a next step, we quantify the exact amount of price discrimination over the price interval for which our results were found to be relevant. Table 5 yields an

\footnotetext{
${ }^{21}$ To calculate the share of $\mathrm{CC}$ in Figure 4 , we rounded the MSRP to $€ 1,000$ and calculated the share of subsidized purchases in 2009 for each $€ 1,000$ price interval.

${ }^{22}$ Even though the distribution is skewed to the right which means that sales do not drop as rapidly as the price rises.
} 


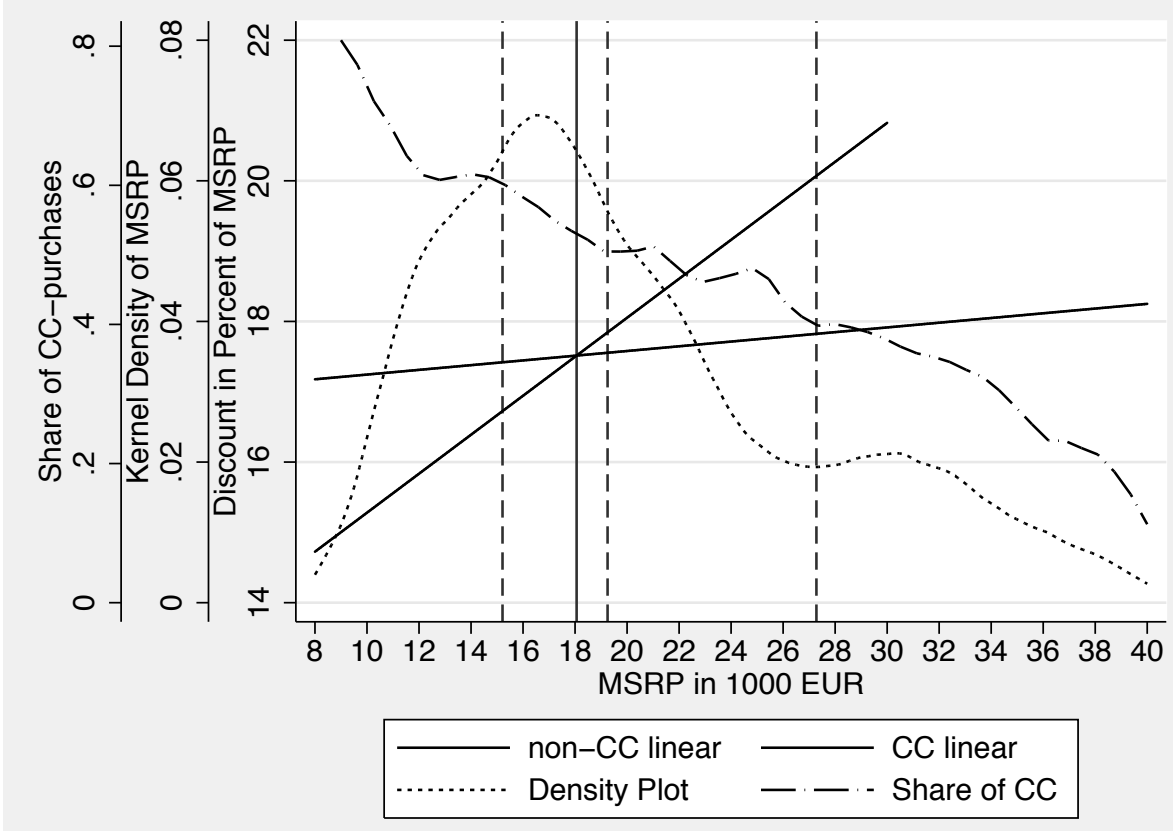

Note: non-CC linear is the function of non-subsidized purchases based on specification (2). CC is the function of the subsidized ones. The density plot refers to the MSRP (manufacturer's suggested retail price) in 2009. To calculate the CC-share, we rounded the MSRP to $€ 1,000$ and calculated the share of subsidized purchases in 2009 for each $€ 1,000$ price interval.

Figure 4: Linear Model with Distribution and CC Share 
Table 5: Price Discrimination over different Prices and Econometric Models

\begin{tabular}{lrrrr}
\hline MSRP & $\begin{array}{r}\text { Linear } \\
(\boldsymbol{\%})\end{array}$ & $\begin{array}{r}\text { Linear } \\
(€)\end{array}$ & $\begin{array}{r}\text { Quadratic } \\
(\mathbf{\%})\end{array}$ & $\begin{array}{r}\text { Quadratic } \\
(€)\end{array}$ \\
\hline 12,000 & -1.48 & -178 & -1.72 & -206 \\
14,000 & -.99 & -139 & -1 & -140 \\
16,000 & -.5 & -80 & -.33 & -53 \\
18,000 & -.01 & -2 & .3 & 54 \\
20,000 & .47 & 94 & .9 & 180 \\
24,000 & 1.45 & 348 & 1.96 & 470 \\
28,000 & 2.42 & 678 & 2.87 & 804 \\
32,000 & 3.4 & 1088 & 3.62 & 1158 \\
\hline
\end{tabular}

Note: The table presents price discrimination in percentage points of MSRP (\%) and Euro (€) based on the linear model from specification (2) or the quadratic model (specification (3)) for a given MSRP.

overview regarding that quantification for the linear and the quadratic model. It provides the percentage (\%) and absolute $(E U R)$ discount received respectively. ${ }^{23}$ The above mentioned intersects are located at the MSRP where the models present a discount of just zero. Comparing the linear to the quadratic model for what we consider the relevant price range, we do not find significant differences: For a car with MSRP of $€ 12,000$, the linear model yields a price discrimination of $-1.48 \%$ or $€-178$, the quadratic model one of $-1,72 \%$ or $€-206$, i.e., a dealer induced skim-off of about $7 \%-8 \%$ of the subsidy amount $(€ 2,500)$. However, the higher-priced cars are more outstanding: a car which cost $€ 28,000$ and therefore is at the lower bound of the fourth quartile of MSRP would benefit from an additional discount of $2.42 \%$ or $€ 687$ in the linear and $2.87 \%$ or $€ 804$ in the quadratic model which means that dealers granted an additional discount of around $27 \%-32 \%$ of the subsidy; a car purchase at the very end of our relevant MSRP range $(€ 32,000)$ did even cause an extra of about 3.5 percentage points or $€ 1,100$ (averaged over the two models), circa $45 \%$ of the scrappage subsidy amount.

${ }^{23}$ The Euro-values were calculated from the corresponding percentage values and the MSRP, not from a separate estimation with discount in Euro as a dependent variable. 


\subsection{Summary}

In summary, our quantitative results are as follows: Linear regression results in which we include only a scrappage dummy - and therefore measure a weighted average over the entire price range - suggest that the demand side not only captured $100 \%$ of the subsidy but benefitted from an additional 0.4 percentage points of discount of MSRP. This result cannot simply be monetarized as it spans over the whole price range and we find that discount in percent rises at a rate of 0.05 percentage points with every $€ 1,000$ of MSRP. Taking into account that the effect is heterogeneous across the price range, we interact the scrappage prime with MSRP. The coefficient for the CC-dummy then becomes -4.4 which means the $\mathrm{y}$-intersect is 4.4 percentage points lower for the $\mathrm{CC}$-function than for the function of non-subsidized purchases. The coefficient of the interaction term is 0.24 , so this function is steeper than the baseline function with a slope of 0.04 (coefficient for MSRP); with every additional $€ 1,000$ of MSRP, the expected discount of subsidized purchases gets $0.24+0,04=0,28$ percentage points bigger. For non-subsidized it grows at the rate 0.04 per $€ 1,000$ of MSRP. All the relevant coefficients are statistically significant at the $1 \%$ level. The function of the subsidized purchases thus starts lower but is steeper, implying that subsidized buyers of cheap cars received a lower and subsidized buyers of expensive cars a higher discount compared to non-subsidized buyers. The functions intersect at an MSRP of $€ 18,000$, denoting the car price where the demand side captures the exact subsidy amount of $€ 2,500$. A quadratic specification does not alter the results.

Demonstration cars earn about 11 percentage points more discount throughout the different specifications compared to standard buyers, company employees about 11.5 percentage points. Relative to base year 2007, discounts were about 0.6 percentage points lower in 2008 and about 1.1 to 1.3 in 2009; these results, too, are statistically significant at the $1 \%$-level. In 2010, the difference was only -0.4 percentage points and hardly statistically significant.

We find that for MSRPs between $€ 12,000$ and $€ 32,000$ there are enough 
data points and the composition is well-balanced between subsidized and nonsubsidized purchases and therefore declare that interval as the relevant price range. For this range, we present figures of price discrimination: according to the linear (quadratic) model, it is $-1.5(-1.7)$ percentage points or $€-178$ $(€-206)$ at a MSRP of $€ 12,000$, about zero percentage points at a price of $€ 18,000(€ 17,000)$ and plus $3.4(3.6)$ percentage points or $€ 1088(€ 1158)$ for an MSRP of $€ 32,000$.

\section{Interpretation}

The main result of this paper is that the incidence of the subsidy strongly and significantly varies across price segments. We focused most of our discussion on three price segments that roughly correspond to the first, second, and third price (MSRP) quartile. In the first quartile that mainly covers mini cars and to some extent small cars, subsidized buyers received slightly lower discounts than non-subsidized ones controlling for covariates. In the second quartile - mainly consisting of small and medium cars - discounts between the two buyer groups did not differ much, implying that the full subsidy amount remained with the buyer. The most striking result was found for sales in the upper half of the price distribution. We focused particularly on the third price quartile (mainly medium and large cars), where subsidized and non-subsidized sales were quite balanced. In this segment, scrappage prime receivers were granted much higher discounts than regular customers. The incidence in this price segment was such that subsidized buyers received huge extra discounts from sellers over and above the government prime.

These findings raise two questions. The first one concerns their compatibility with the results of Busse et al. (2006) and Sallee (2011) on the incidence of auto manufacturer promotions and tax credits. The second question is: What do these results imply about price discrimination in the automobile market?

Our result for the lower price segments-loosely speaking for the bottom 
half of the distribution - is broadly in line with the results in Busse et al. (2006) and Sallee (2011). Busse et al. (2006) find that between $70 \%$ and $90 \%$ of the customer promotion amount remains with the buyer, i.e., the seller reaps only a small fraction of the promotion. Since a customer promotion is quite comparable to a buyer subsidy granted by the government, the two instruments are in fact comparable and so are our results of roughly $90 \%$ pass-through to buyers in the first quartile. Sallee (2011) finds that a customer directed tax subsidy for the Toyota Prius, a small car that would fall into our second price quartile, is fully captured by customers although sellers face a binding production constraint. In the case of the German scrappage prime, a production constraint was also binding in the small-car segment since the subsidy caused a run on these cars. Our results in the second price quartile are therefore fully in line with Sallee's results and in fact as surprising as his findings. While his explanation builds mainly on long-run pricing policy of manufacturer's we conjecture that in the German case, increased competition due to the demand shock induced by the government intervention additionally explains why the supply-side only captured a small or even negligible fraction of the subsidy in the bottom half of the distribution.

In fact, the whole discount and pricing pattern in the German 2009 car market can be explained by price discrimination - the second question we previously raised - that depends on market conditions in different market segments. With regard to the lower price segment two observations are crucial. On the one hand, the scrappage program shifted demand heavily towards smaller cars. This gave dealers some market power and thus allowed for price making. Additionally, dealers were able to identify two groups with a different price elasticity of demand in this segment, namely subsidized and non-subsidized buyers. In contrast to non-subsidized customers, buyers receiving the subsidy and aiming at this market segment were presumably relatively more price-inelastic since the subsidy was available only for a very short period of time and because people were keen on seizing the opportunity of grabbing a $€ 2,500$ check. In addition, 
close substitutes for mini and small cars were not available since downgrading was hardly possible and the demand shock essentially affected all brands alike. Altogether, this suggests that there was room for price discrimination based on observables (the scrappage prime information) in the lower price segment. On the other hand, it is well-known that competition in the market for small cars is quite high (see e.g. Sudhir (2001) for US evidence) and competition presumably increased in 2009 due to the scrappage subsidy. However, competition limits the scope for price discrimination. In particular, in a competitive market where brand loyalty is not (yet) established, price elasticity is presumably not spectacularly different across buyer groups. Dealers and manufactures contemplating to enforce higher markups for subsidy receivers therefore had to trade off higher margins against lower sales in the short run. Also, long-run pricing considerations along the lines of Sallee (2011) may have played a role in the pricing policy. Together, this explains why there was some price discrimination against scrappage prime receivers but less than one may have expected a priori, leaving the bulk of the subsidy with buyers of small cars.

Things were very different in the upper price segment. Here, the market was slack and unsold cars were piling up. From an upper-segment car dealer's perspective an interesting and unique potentially profit maximizing strategy was possible due to the subsidy. In a nutshell, customers aiming at the large-car segment could be divided into two observable groups with different price elasticities of demand, namely regular large-car buyers who tended not to receive the subsidy and subsidized buyers who would typically not buy a large car. First, non-subsidized (regular) customers in the upper price segment did not receive exceptional rebates since that would interfere with the well-known cooperative pricing strategy of car manufacturers towards brand loyal long-term customers (see e.g. Sudhir (2001)). This would have unnecessarily eroded margins without increasing long-term demand in that customer segment. In fact, interviews with car dealers suggest that a selection effect was working in their favor. Subsidized buyers were typically not customers for pricey cars and would usually not up- 
grade from a clunker to a new expensive car. Therefore, their price elasticity of demand for large cars was quite high which lead dealers to offer exceptionally high discounts to this customer group, consistent with our findings. Offering high rebates to subsidized customers on the other hand did not interfere with long-run pricing considerations of manufacturers since the new customer group was a one-time target without any significant downside risk with regard to their long-run car demand for large-car manufacturers.

In summary, our results on the incidence of the scrappage subsidy are in line with an optimal long-run pricing strategy of manufacturers and dealers in the car market. Firms in the small-car segments tend to be aggressive and room for price discrimination based on observable characteristics - such as the information of receiving the scrappage prime - is limited due to strong competition. This is in line with our finding that in the lower half of the price distribution the bulk of the scrappage subsidy remained with the buyer. With regard to the larger-car segments, aggressive pricing is usually avoided since aggressive pricing reduces margins without increasing demand of regular customers who tend to be very brand loyal in that market segment. However, granting huge discounts to a new, observable group of customers who could be distinguished from the old and loyal ones based on the scrappage prime information offered a one-time opportunity to increase profits for large-car manufacturers and dealers by increasing sales. This is in line with our main finding that subsidized buyers of large cars eventually received extra discounts on top of the the scrappage subsidy amount.

\section{Sensitivity Analysis}

A possible concern is that the results are either driven by neglected time-effects or by subgroups. We therefore present sensitivity checks including additional time controls or restricting the data to 2009; after that, we successively drop subsets of the data which might be driving the results. Table 6 sums up the tests we ran on our data sample. It reports the most relevant figures: the number of 
observations $(O b s)$, the intersect, i.e., the point where there is no difference in discount between a subsidized and a non-subsidized car (Int), the coefficient for the scrappage prime $(C C)$, the coefficient of the interaction term $\left(C C^{*} M S R P\right)$, and the percentage levels of price discrimination for $\mathrm{a} € 12,000, \mathrm{a} € 18,000$, and a $€ 32,000$ car purchase (PD12, PD18 and PD32).

The first row represents the linear model based on the full data, i.e., the reference results from specification (2) in Table 4. In the following row, we additionally add two time controls to the model: a dummy for the switch from the paper-based to the electronic subsidy application procedure (Time 1) and a time dummy for the expansion of the program from $€ 1.5$ to $€ 5$ Billion (Time 2). One can see that the inclusion of these further controls does not alter the results significantly.

In the third row, we restrict our sample to year 2009 only. While the price discrimination measured for an MSRP of $€ 12,000$ is slightly lower, the overall pattern remains the same. This indicates that we do not simply observe a difference because 2009 was very special but that the hypothesis of price discrimination actually holds.

As discussed on page 12, we need to make sure that our results are not driven by composition effects stemming from unequal shares of high-discount groups. In addition to correcting for different levels of discount (note that the coefficients are very stable over all considered specifications), we exclude both groups from the regression: first, company employees ( $N o C E$, fourth row), then demonstration cars (No $D C$, fifth row) and, in row 6 , both. None of these exclusion changes the results significantly.

In row 7 , we exclude the three vehicle classes that do not enter the "natural" order, i.e., SUVs $(J)$, MPVs $(M)$ and Sports Coupés $(S) .{ }^{24}$ Still, our essential results remain valid.

Rows 8-14 show the results when leaving out single brand-dealers. They illustrate that the results of our analysis are not driven by a single group of those

${ }^{24}$ The other vehicle classes are cardinally by size and, most important, price. The three excluded vehicle classes are not part of this order and might be special for various reasons. 
Table 6: Sensitivity Checks - Overview

\begin{tabular}{|c|c|c|c|c|c|c|c|c|}
\hline No & Case & Obs & Int & $\mathrm{CC}$ & $\begin{array}{l}\mathrm{CC}^{*} \\
\text { MSRP }\end{array}$ & PD12 & PD18 & PD32 \\
\hline 1 & All data & 8156 & 18.06 & -4.4 & .24 & -1.48 & -.01 & 3.4 \\
\hline 2 & Time 1 and 2 & 8156 & 18.47 & -4.73 & .26 & -1.66 & -.12 & 3.47 \\
\hline 3 & 2009 only & 3190 & 17.28 & -3.01 & .17 & -.92 & .13 & 2.56 \\
\hline 4 & No CE & 7188 & 18.85 & -4.77 & .25 & -1.73 & -.21 & 3.33 \\
\hline 5 & No DC & 6836 & 16.76 & -4.49 & .27 & -1.28 & .33 & 4.09 \\
\hline 6 & No CE, no DC & 5868 & 17.56 & -4.96 & .28 & -1.57 & .12 & 4.08 \\
\hline 7 & No VC J, M, S & 6059 & 16.29 & -3.9 & .24 & -1.03 & .41 & 3.77 \\
\hline 8 & No BD1 & 6692 & 17.58 & -3.92 & .22 & -1.24 & .09 & 3.21 \\
\hline 9 & No BD2 & 5990 & 18.72 & -4.43 & .24 & -1.59 & -.17 & 3.15 \\
\hline 10 & No BD3 & 6657 & 15.76 & -3.29 & .21 & -.78 & .47 & 3.38 \\
\hline 11 & No BD4 & 7862 & 17.89 & -4.4 & .25 & -1.45 & .03 & 3.47 \\
\hline 12 & No BD5 & 8010 & 18.37 & -4.52 & .25 & -1.57 & -.09 & 3.35 \\
\hline 13 & No BD6 & 6288 & 16.61 & -4.49 & .27 & -1.24 & .38 & 4.16 \\
\hline 14 & No BD7 & 7437 & 20.95 & -5.74 & .27 & -2.45 & -.81 & 3.02 \\
\hline
\end{tabular}

Note: All data is the regression presented above as a benchmark for the sensitivity tests. Time 1 and 2 includes two time controls for program changes (electronic application procedure and budget increase, 2009 only is a restriction to year 2009 only. Lines 4 to 14 present the exclusion of different groups: $C E=$ company employees and $D C=$ demonstration cars are high discount receivers, ( $V C$ $J, M, S)$ are the three vehicle classes which are not part of a natural order, i.e. MPVs $(M)$, SUVs $(J)$, and Sports Coupés $(S)$. BD1 to $B D 7$ are different brand-dealer combinations.

categories. The intersect is rather stable over the different data restrictions: it may fall down to about $€ 16,000$ (row 10) but can also move up to roughly $€ 21,000$ (row 14). On average, however, it is located around $€ 17,000$ to 18,000 and therefore meets the dimension of our full model. ${ }^{25}$

Overall, Table 6 demonstrates that our findings are robust to an extensive variety of sensitivity checks. It is unlikely that the presented estimation results are caused by ignored program influences, differences over time, high discount groups or special vehicle classes, as well as single dealers or brands.

\section{Conclusion}

We evaluate the incidence of the German scrappage program from 2009, the most expensive program of all countries in that time period with a total volume

\footnotetext{
${ }^{25}$ Regression tables including time controls and excluding high discount groups are reported in the appendix. The less relevant tables excluding single brand-dealers and restricting to year 2009 only are available upon request.
} 
of $€ 5$ billion ( $\$ 7$ billion). Applying linear regression models to a unique sample of micro transaction data we model the percentage discount as a function of the MSRP, a dummy for the scrapping prime, and various controls. In a first step, we surprisingly find that the subsidy is captured by the customers by slightly more than $100 \%$. We therefore allow for heterogeneity across price segments when comparing subsidized to non-subsidized purchases and find that these differ significantly. Subsidized buyers of the first quartile (cheap cars) faced negative price discrimination, i.e., received less discount than non-subsidized buyers. For $\mathrm{a} € 12,000$ car purchase about 1.6 percentage points of the MSRP were skimmed off by car dealers. This implies that dealers captured approximately $8 \%$ of the subsidy. Somewhere in the second quartile, for a price of about $€ 18,000$, we observe no pass-through meaning that customers captured the entire subsidy of $€ 2,500$. Above the median MSRP, the discount for subsidized buyers was higher than the discount for non-subsidized ones. For a $€ 32,000$ car, dealers granted an extra 3.5 percentage points of the MSRP or about $45 \%$ of the subsidy, i.e., they granted an extra discount of roughly $€ 1,100$ to attract customers receiving the subsidy in comparison to those who did not.

This pattern can be explained by price discrimination depending on market conditions in different market segments. The scrappage program shifted demand heavily towards the lowest price segment (small cars) giving dealers some market power in this quite segmented market which allowed for price making. Additionally, dealers were able to identify two groups with a different price elasticity of demand. The group of subsidized buyers was eager to buy a new - and due to the subsidy - very cheap car and therefore tended to be comparatively less price sensitive. In contrast to this, the other group of non-subsidized buyers was more price sensitive. Therefore, in this price segment car dealers were able to enforce a price-markup for the subsidized group by granting lower discounts compared to non-subsidized buyers. In the upper price segment (large cars), demand was slack due to the financial crisis and therefore stocks were piling up. Dealers used additional discounts in order to attract the subsidized buyer 
group who would have otherwise tended to buy a car in a lower price segment (medium cars). In the upper price segment, receiving the subsidy therefore revealed relatively high price elasticity because market segmentation did not exist or was not perfect.

Finally, our estimation results turn out to be extremely robust to all kinds of data restrictions as well as model modifications. 


\section{Appendix}

\subsection{Appendix 1: Data}

Table 7: Number of Purchases over Car Brands and Car Dealers

\begin{tabular}{lrrrrrrr}
\hline Car Dealer & $\mathbf{1}$ & $\mathbf{2}$ & $\mathbf{3}$ & $\mathbf{4}$ & $\mathbf{5}$ & $\mathbf{6}$ & Total \\
\hline Dealer 1 & 0 & 2166 & 0 & 0 & 0 & 0 & 2166 \\
Dealer 2 & 1464 & 0 & 0 & 0 & 0 & 0 & 1464 \\
Dealer 3 & 0 & 1499 & 0 & 0 & 0 & 0 & 1499 \\
Dealer 4 & 0 & 0 & 0 & 0 & 1868 & 0 & 1868 \\
Dealer 5 & 0 & 0 & 294 & 0 & 0 & 0 & 294 \\
Dealer 6 & 0 & 0 & 0 & 146 & 0 & 719 & 865 \\
Total & 1464 & 3665 & 294 & 146 & 1868 & 719 & 8156 \\
\hline
\end{tabular}

Table 8: Number of Purchases over Month of all Years, 2009 by CC

\begin{tabular}{lrrrrr}
\hline & \multicolumn{5}{c}{ Year of Purchase and Clunker's Prime } \\
& $\mathbf{2 0 0 7}$ & $\mathbf{2 0 0 8}$ & $\mathbf{2 0 0 9}$ & $\mathbf{2 0 0 9}$ & $\mathbf{2 0 1 0}$ \\
Month of Purchase & & & Non- & CC & \\
& & & CC & & \\
\hline 1 & 103 & 109 & 115 & 25 & 101 \\
2 & 85 & 132 & 139 & 93 & 120 \\
3 & 162 & 175 & 183 & 206 & 230 \\
4 & 154 & 225 & 157 & 200 & 159 \\
5 & 147 & 159 & 115 & 221 & 183 \\
6 & 142 & 172 & 156 & 198 & 166 \\
7 & 118 & 149 & 129 & 192 & 133 \\
8 & 116 & 85 & 107 & 150 & 133 \\
9 & 140 & 115 & 136 & 102 & 129 \\
10 & 109 & 145 & 145 & 100 & 143 \\
11 & 134 & 120 & 137 & 41 & 114 \\
12 & 144 & 115 & 130 & 13 & 100 \\
Total & 1554 & 1701 & 1649 & 1541 & 1711 \\
\hline
\end{tabular}


Table 9: Summary Statistics: 2009 only

\begin{tabular}{lrrrrrr}
\hline Variables & Mean & SD & Med & Min & Max & N \\
\hline Discount in Percent & 17.11 & 7.82 & 16.75 & 0.00 & 45.61 & 3,190 \\
Discount in 1000 EUR & 3.99 & 3.20 & 3.25 & 0.00 & 51.81 & 3,190 \\
MSRP in 1000 EUR & 23.02 & 12.76 & 19.25 & 8.69 & 130.35 & 3,190 \\
Clunker's Prime (CC) & 0.48 & 0.50 & 0 & 0 & 1 & 3,190 \\
Demonstration Car (DC) & 0.14 & 0.35 & 0 & 0 & 1 & 3,190 \\
Company Employee (CE) & 0.13 & 0.33 & 0 & 0 & 1 & 3,190 \\
Female & 0.32 & 0.46 & 0 & 0 & 1 & 3,190 \\
Age at Purchase & 46.79 & 15.09 & 48 & 18 & 89 & 639 \\
\hline
\end{tabular}

Note: MSRP is the manufacturer suggested retail price. DC is a dummy variable indicating whether a buyer bought a demonstration car $(D C=1)$. CE is a dummy variable indicating whether the buyer was an employee of a car manufacturing company $(C E=1)$. $C C$ is a dummy variable indicating whether the buyer of a car received the scrappage subsidy $(C C=1)$. Female is a dummy of female buyers, the summary statistics therefore report the share of women.

Table 10: Summary Statistics over vehicle class

\begin{tabular}{lccr}
\hline & \multicolumn{2}{c}{ Catalog price in $\mathbf{1 . 0 0 0}$ EUR } & \\
EU Vehicle Class & Mean & SD & N \\
\hline A - Mini Cars & 11.59 & 1.29 & 649 \\
B - Small Cars & 16.09 & 2.59 & 2611 \\
C - Medium Cars & 23.76 & 4.22 & 1649 \\
D - Large Cars & 38.94 & 7.87 & 899 \\
E - Executive Cars & 58.32 & 11.54 & 232 \\
F - Luxury Cars & 106.91 & 15.54 & 19 \\
J - SUV & 40.18 & 14.68 & 481 \\
M - MPV & 27.25 & 7.28 & 1429 \\
S - Sports Coupés & 61.09 & 25.51 & 187 \\
Total & 25.62 & 14.37 & 8156 \\
\hline
\end{tabular}

Note: $S U V$ stands for Sport Utility Vehicle, $M P V$ for Multi Purpose Vehicle.

Table 11: Percentage Discount over Time by CC

\begin{tabular}{|c|c|c|c|c|c|c|}
\hline \multirow[b]{3}{*}{ Year of Purchase } & \multicolumn{6}{|c|}{ Discount in Percent } \\
\hline & Non-C & & $\mathrm{CC}$ & & Total & \\
\hline & MeanSD & $\mathbf{N}$ & MeanSD & $\mathbf{N}$ & MeanSD & $\mathbf{N}$ \\
\hline 2007 & 15.699 .01 & 1554 & & 0 & 15.699 .01 & 1554 \\
\hline 2008 & 16.549 .64 & 1701 & & 0 & 16.549 .64 & 1701 \\
\hline 2009 & 17.678 .73 & 1649 & 16.516 .67 & 1541 & 17.117 .82 & 3190 \\
\hline 2010 & 18.038 .74 & 1711 & & 0 & 18.038 .74 & 1711 \\
\hline Total & 17.019 .09 & 6615 & 16.516 .67 & 1541 & 16.918 .68 & 8156 \\
\hline
\end{tabular}

Note: Non-CC are non-subsidized purchases, CC subsidized ones. The last part of the table gives summary statistics for the whole group. 
Table 12: Percentage Discount by Purchase Types

\begin{tabular}{lccr}
\hline & \multicolumn{2}{c}{ Discount in Percent } \\
Type of Purchase & Mean & SD & N \\
\hline Standard & 14.02 & 7.44 & 5868 \\
Company Employee & 25.84 & 4.03 & 968 \\
Demonstration Car & 23.25 & 8.47 & 1320 \\
Total & 16.91 & 8.68 & 8156 \\
\hline
\end{tabular}

Note: Standard are the benchmark purchases, Company Employees are employees of a car manufacturing company, Demonstration Car denotes cars that are not new but have been used for exposition. 

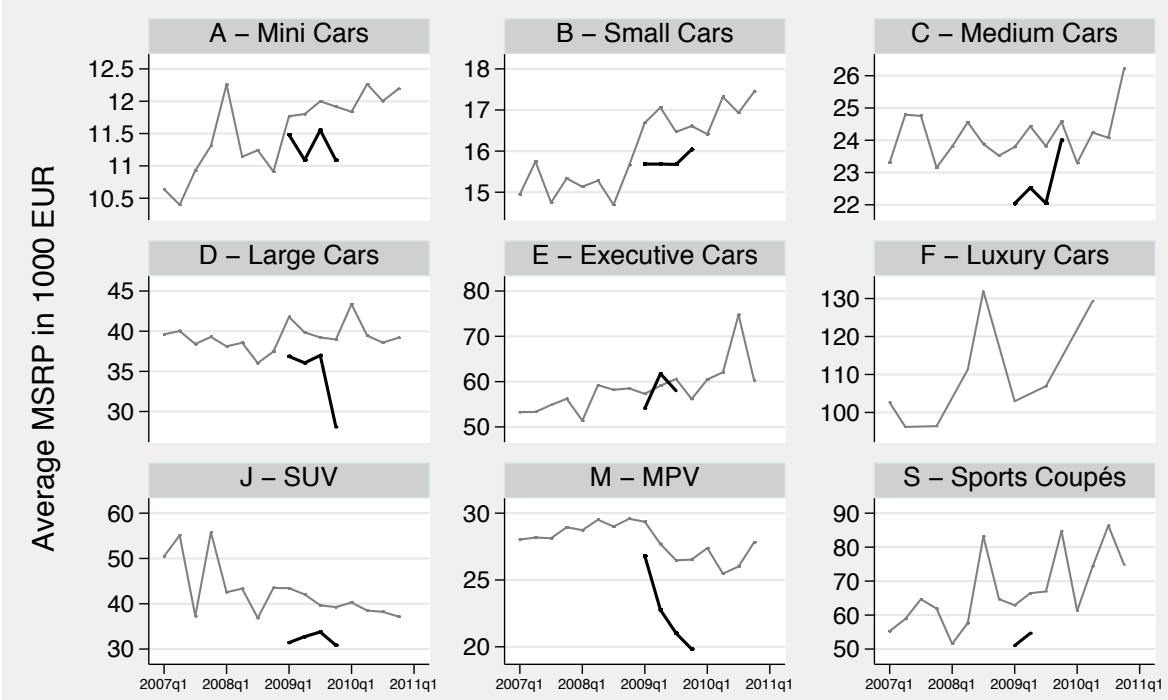

Quarter of Purchase

Non-CC transactions

CC transactions

Note: $S U V$ stands for Sport Utility Vehicle, $M P V$ for Multi Purpose Vehicle.

Figure 5: MSRP over Time by EU-Vehicle Class 


\subsection{Appendix 2: Sensitivity analysis}

\subsubsection{Regressions including time controls}

Table 13: Including time controls

All transactions with time controls

Dependent variable: Discount in Percent of MSRP

\begin{tabular}{|c|c|c|c|}
\hline VARIABLES & (1) & $(2)$ & $(3)$ \\
\hline $\mathrm{CC}$ & $\begin{array}{c}0.320 \\
(0.234)\end{array}$ & $\begin{array}{c}-4.729 * * * \\
(0.506)\end{array}$ & $\begin{array}{c}-7.3795^{* * *} \\
(1.3129)\end{array}$ \\
\hline CC*MSRP & & $\begin{array}{c}0.256^{* * *} \\
(0.0231)\end{array}$ & $\begin{array}{c}0.5174^{* * * *} \\
(0.1211)\end{array}$ \\
\hline$\left(\mathrm{CC}^{*} \mathrm{MSRP}\right)^{2}$ & & & $\begin{array}{c}-0.0053^{* *} \\
(0.0026)\end{array}$ \\
\hline MSRP & $\begin{array}{c}0.0444^{* * *} \\
(0.00815)\end{array}$ & $\begin{array}{c}0.0319 * * * \\
(0.00797)\end{array}$ & $\begin{array}{c}0.0836^{* * *} \\
(0.0172)\end{array}$ \\
\hline $\mathrm{MSRP}^{2}$ & & & $\begin{array}{c}-0.0005^{* * *} \\
(0.0002)\end{array}$ \\
\hline $\mathrm{DC}$ & $\begin{array}{c}10.96^{* * *} \\
(0.279)\end{array}$ & $\begin{array}{c}10.82^{* * *} \\
(0.277)\end{array}$ & $\begin{array}{c}10.7976 * * * \\
(0.2760)\end{array}$ \\
\hline $\mathrm{CE}$ & $\begin{array}{c}11.52^{* * *} \\
(0.312)\end{array}$ & $\begin{array}{c}11.59^{* * * *} \\
(0.310)\end{array}$ & $\begin{array}{c}11.5761^{* * *} \\
(0.3113)\end{array}$ \\
\hline Year $=2008$ & $\begin{array}{c}-0.633^{* * *} \\
(0.231)\end{array}$ & $\begin{array}{c}-0.655^{* * *} \\
(0.230)\end{array}$ & $\begin{array}{c}-0.6759 * * * \\
(0.2300)\end{array}$ \\
\hline Year $=2009$ & $\begin{array}{c}-2.692^{* * *} \\
(0.354)\end{array}$ & $\begin{array}{c}-2.953^{* * *} \\
(0.353)\end{array}$ & $\begin{array}{c}-2.9664^{* * *} \\
(0.3512)\end{array}$ \\
\hline Year $=2010$ & $\begin{array}{l}-0.383 \\
(0.243)\end{array}$ & $\begin{array}{c}-0.453^{*} \\
(0.242)\end{array}$ & $\begin{array}{c}-0.4309^{*} \\
(0.2426)\end{array}$ \\
\hline Constant & $\begin{array}{c}18.16^{* * *} \\
(1.640)\end{array}$ & $\begin{array}{c}18.60^{* * *} \\
(1.638)\end{array}$ & $\begin{array}{c}17.6703^{* * *} \\
(1.6593)\end{array}$ \\
\hline Observations & 8,156 & 8,156 & 8,156 \\
\hline Adjusted R-squared & 0.490 & 0.499 & 0.5008 \\
\hline Month dummies & Yes & Yes & Yes \\
\hline Sex dummy & Yes & Yes & Yes \\
\hline Seller dummies & Yes & Yes & Yes \\
\hline Dealer dummies & Yes & Yes & Yes \\
\hline Time $1+2$ & Yes & Yes & Yes \\
\hline Intersect & $\mathrm{n} / \mathrm{a}$ & 18.47 & 17.38 \\
\hline
\end{tabular}

Note: $* * *$ significant at the $1 \%$-level, ** significant at the $5 \%$-level, $*$ significant at the $10 \%$ level. Robust standard errors (HC3) in parentheses. CC: dummy for subsidized (Cash-for-Clunkers) transaction, MSRP: Manufacturer's suggested retail price in $€ 1000$, DC: dummy for demonstration car, CE: dummy for employees of auto manufacturing companies. Year $=2008$ (2009) (2010) are dummy variables for the given years, 2007 is the base year. Intersect indicates where the estimated function for subsidized purchases is equal to the baseline function. 


\subsubsection{Regressions excluding company employees and demonstration}

cars

Table 14: All but company employees

Without company employees

Dependent variable: Discount in Percent of MSRP

\begin{tabular}{|c|c|c|c|}
\hline VARIABLES & (1) & $(2)$ & $(3)$ \\
\hline $\mathrm{CC}$ & $\begin{array}{c}0.304 \\
(0.267)\end{array}$ & $\begin{array}{c}-4.768^{* * *} \\
(0.554)\end{array}$ & $\begin{array}{c}-7.5289 * * * \\
(1.4155)\end{array}$ \\
\hline $\mathrm{CC}^{*} \mathrm{MSRP}$ & & $\begin{array}{c}0.253^{* * *} \\
(0.0242)\end{array}$ & $\begin{array}{c}0.5303^{* * *} \\
(0.1286)\end{array}$ \\
\hline$\left(\mathrm{CC}^{*} \mathrm{MSRP}\right)^{2}$ & & & $\begin{array}{c}-0.0057^{* *} \\
(0.0027)\end{array}$ \\
\hline MSRP & $\begin{array}{c}0.0482 * * * \\
(0.00874)\end{array}$ & $\begin{array}{c}0.0365 * * * \\
(0.00850)\end{array}$ & $\begin{array}{c}0.1062^{* * *} \\
(0.0191)\end{array}$ \\
\hline $\mathrm{MSRP}^{2}$ & & & $\begin{array}{c}-0.0007^{* * *} \\
(0.0002)\end{array}$ \\
\hline $\mathrm{DC}$ & $\begin{array}{c}10.95^{* * *} \\
(0.277)\end{array}$ & $\begin{array}{c}10.81^{* * * *} \\
(0.276)\end{array}$ & $\begin{array}{c}10.7782^{* * *} \\
(0.2746)\end{array}$ \\
\hline Year $=2008$ & $\begin{array}{c}-0.936^{* * *} \\
(0.246)\end{array}$ & $\begin{array}{c}-0.953^{* * *} \\
(0.245)\end{array}$ & $\begin{array}{c}-0.9769 * * * \\
(0.2452)\end{array}$ \\
\hline Year $=2009$ & $\begin{array}{c}-0.703^{* * *} \\
(0.268)\end{array}$ & $\begin{array}{c}-0.725^{* * *} \\
(0.268)\end{array}$ & $\begin{array}{c}-0.7490^{* * *} \\
(0.2667)\end{array}$ \\
\hline Year $=2010$ & $\begin{array}{r}-0.0395 \\
(0.263)\end{array}$ & $\begin{array}{l}-0.114 \\
(0.262)\end{array}$ & $\begin{array}{l}-0.0956 \\
(0.2621)\end{array}$ \\
\hline Constant & $\begin{array}{c}17.38 * * * \\
(1.676)\end{array}$ & $\begin{array}{c}17.74^{* * * *} \\
(1.678)\end{array}$ & $\begin{array}{c}16.4819 * * * \\
(1.7056)\end{array}$ \\
\hline Observations & 7,188 & 7,188 & 7,188 \\
\hline Adjusted R-squared & 0.415 & 0.424 & 0.4278 \\
\hline Month dummies & Yes & Yes & Yes \\
\hline Sex dummy & Yes & Yes & Yes \\
\hline Seller dummies & Yes & Yes & Yes \\
\hline Dealer dummies & Yes & Yes & Yes \\
\hline Intersect & $\mathrm{n} / \mathrm{a}$ & 18.85 & 17.48 \\
\hline
\end{tabular}

Note: *** significant at the $1 \%$-level, ** significant at the $5 \%$-level, $*$ significant at the $10 \%$ level. Robust standard errors (HC3) in parentheses. CC: dummy for subsidized (Cash-for-Clunkers) transaction, MSRP: Manufacturer's suggested retail price in $€ 1000$, DC: dummy for demonstration car, CE: dummy for employees of auto manufacturing companies. Year $=2008$ (2009) (2010) are dummy variables for the given years, 2007 is the base year. Intersect indicates where the estimated function for subsidized purchases is equal to the baseline function. 
Table 15: All but demonstration cars

Without demonstration cars

Dependent variable: Discount in Percent of MSRP

\begin{tabular}{|c|c|c|c|}
\hline VARIABLES & (1) & $(2)$ & (3) \\
\hline $\mathrm{CC}$ & $\begin{array}{c}0.581^{* *} \\
(0.236)\end{array}$ & $\begin{array}{c}-4.495^{* * *} \\
(0.531)\end{array}$ & $\begin{array}{c}-10.1162^{* * *} \\
(1.0468)\end{array}$ \\
\hline $\mathrm{CC}^{*} \mathrm{MSRP}$ & & $\begin{array}{c}0.268^{* * *} \\
(0.0251)\end{array}$ & $\begin{array}{c}0.8296^{* * *} \\
(0.0928)\end{array}$ \\
\hline$\left(\mathrm{CC}^{*} \mathrm{MSRP}\right)^{2}$ & & & $\begin{array}{c}-0.0122^{* * *} \\
(0.0020)\end{array}$ \\
\hline MSRP & $\begin{array}{c}0.0557^{* * *} \\
(0.00870)\end{array}$ & $\begin{array}{c}0.0395 * * * \\
(0.00837)\end{array}$ & $\begin{array}{c}0.0675^{* * *} \\
(0.0178)\end{array}$ \\
\hline $\mathrm{MSRP}^{2}$ & & & $\begin{array}{c}-0.0003^{*} \\
(0.0002)\end{array}$ \\
\hline $\mathrm{CE}$ & $\begin{array}{c}11.52^{* * * *} \\
(0.311)\end{array}$ & $\begin{array}{c}11.60^{* * *} \\
(0.311)\end{array}$ & $\begin{array}{c}11.6210^{* * *} \\
(0.3118)\end{array}$ \\
\hline Year $=2008$ & $\begin{array}{c}-1.325^{* * * *} \\
(0.242)\end{array}$ & $\begin{array}{c}-1.340^{* * * *} \\
(0.241)\end{array}$ & $\begin{array}{c}-1.3310^{* * * *} \\
(0.2415)\end{array}$ \\
\hline Year $=2009$ & $\begin{array}{c}-2.056^{* * *} \\
(0.253)\end{array}$ & $\begin{array}{c}-2.092^{* * *} \\
(0.253)\end{array}$ & $\begin{array}{c}-2.0532^{* * *} \\
(0.2529)\end{array}$ \\
\hline Year $=2010$ & $\begin{array}{c}-1.037^{* * *} \\
(0.251)\end{array}$ & $\begin{array}{c}-1.096^{* * *} \\
(0.250)\end{array}$ & $\begin{array}{c}-1.0520^{* * *} \\
(0.2505)\end{array}$ \\
\hline Constant & $\begin{array}{c}23.51^{* * * *} \\
(3.917)\end{array}$ & $\begin{array}{c}23.89^{* * * *} \\
(3.928)\end{array}$ & $\begin{array}{c}23.3772^{* * *} \\
(3.9484)\end{array}$ \\
\hline Observations & 6,836 & 6,836 & 6,836 \\
\hline Adjusted R-squared & 0.490 & 0.499 & 0.5026 \\
\hline Month dummies & Yes & Yes & Yes \\
\hline Sex dummy & Yes & Yes & Yes \\
\hline Seller dummies & Yes & Yes & Yes \\
\hline Dealer dummies & Yes & Yes & Yes \\
\hline Intersect & $\mathrm{n} / \mathrm{a}$ & 16.76 & 15.93 \\
\hline
\end{tabular}

Note: *** significant at the $1 \%$-level, ** significant at the $5 \%$-level, $*$ significant at the $10 \%$ level. Robust standard errors (HC3) in parentheses. CC: dummy for subsidized (Cash-for-Clunkers) transaction, MSRP: Manufacturer's suggested retail price in $€ 1000$, DC: dummy for demonstration car, CE: dummy for employees of auto manufacturing companies. Year $=2008(2009)(2010)$ are dummy variables for the given years, 2007 is the base year. Intersect indicates where the estimated function for subsidized purchases is equal to the baseline function. 
Table 16: All but company employees and demonstration cars

ithout company employees and demonstration cars

Dependent variable: Discount in Percent of MSRP

\begin{tabular}{lccc}
\hline & $(1)$ & $(2)$ & $(3)$ \\
VARIABLES & & & \\
CC & $0.468^{*}$ & $-4.957^{* * *}$ & $-11.0746^{* * *}$ \\
& $(0.278)$ & $(0.598)$ & $(1.1582)$ \\
CC*MSRP & & $0.282^{* * *}$ & $0.8963^{* * *}$ \\
& & $(0.0272)$ & $(0.1018)$ \\
$(\mathrm{CC} * \mathrm{MSRP})^{2}$ & & & $-0.0134^{* * *}$ \\
& & & $(0.0022)$ \\
MSRP & $0.0623^{* * *}$ & $0.0457^{* * *}$ & $0.0919^{* * *}$ \\
& $(0.00972)$ & $(0.00924)$ & $(0.0179)$ \\
MSRP & & & $-0.0005^{* * *}$ \\
& & & $(0.0001)$ \\
Year $=2008$ & $-1.782^{* * *}$ & $-1.801^{* * *}$ & $-1.7929^{* * *}$ \\
& $(0.261)$ & $(0.260)$ & $(0.2608)$ \\
Year $=2009$ & $-1.651^{* * *}$ & $-1.681^{* * *}$ & $-1.6452^{* * *}$ \\
& $(0.285)$ & $(0.285)$ & $(0.2846)$ \\
Year $=2010$ & $-0.715^{* * *}$ & $-0.785^{* * *}$ & $-0.7361^{* * *}$ \\
& $(0.276)$ & $(0.275)$ & $(0.2752)$ \\
Constant & $7.254^{* * *}$ & $7.539^{* * *}$ & $6.8425^{* * *}$ \\
& $(0.595)$ & $(0.511)$ & $(0.6560)$ \\
& & & \\
Observations & 5,868 & 5,868 & 5,868 \\
Adjusted R-squared & 0.330 & 0.343 & 0.3497 \\
\hline Month dummies & Yes & Yes & Yes \\
Sex dummy & Yes & Yes & Yes \\
Seller dummies & Yes & Yes & Yes \\
Dealer dummies & Yes & Yes & Yes \\
Intersect & n/a & 17.56 & 16.34 \\
\hline & & & \\
\hline
\end{tabular}

Note: $* * *$ significant at the $1 \%$-level, ** significant at the $5 \%$-level, $*$ significant at the $10 \%-$ level. Robust standard errors (HC3) in parentheses. CC: dummy for subsidized (Cash-for-Clunkers) transaction, MSRP: Manufacturer's suggested retail price in $€ 1000$, DC: dummy for demonstration car, CE: dummy for employees of auto manufacturing companies. Year $=2008$ (2009) (2010) are dummy variables for the given years, 2007 is the base year. Intersect indicates where the estimated function for subsidized purchases is equal to the baseline function. 


\section{References}

Adda, Jerome and Russell Cooper, "Balladurette and Juppette: A Discrete Analysis of Scrapping Subsidies," Journal of Political Economy, August 2000, $108(4), 778-806$.

Busse, Meghan, Jorge Silva-Risso, and Florian Zettelmeyer, " $\$ 1,000$ Cash Back: The Pass-Through of Auto Manufacture Promotions," The American Economic Review, September 2006, 96 (4), 1253-1253.

Chetty, Raj, Adam Looney, and Kory Kroft, "Salience and Taxation: Theory and Evidence.," The American Economic Review, 2009, 99 (4), 11451177.

Deysher, Beth and Don Pickrell, "Emissions Reductions From Vehicle Retirement Programs," Transportation Research Record: Journal of the Transportation Research Board, 1997, 1587, 121-127.

Esteban, Susanna, "Effective Scrappage Subsidies.," The B.E. Journal of Theoretical Economics: Contributions to Theoretical Economics, 2007, 7 (1), 1-30.

_ and Matthew Shum, "Durable-Goods Oligopoly with Secondary Markets: The Case of Automobiles," The RAND Journal of Economics, 2007, 38 (2), 332-354.

Evans, William N., Jeanne S. Ringel, and Diana Stech, "Tobacco Taxes and Public Policy to Discourage Smoking," in "Tax Policy and the Economy," Vol. 13 of NBER Chapters, National Bureau of Economic Research, Inc, 1999, pp. $1-56$.

Friedman, John, "The Incidence of the Medicare Prescription Drug Benefit: Using Asset Prices to Assess its Impact on Drug Makers," 2009. Working Paper, Harvard Kennedy School, Harvard University. 
Fullerton, Don and Gilbert E. Metcalf, "Tax Incidence," in Alan J. Auerbach and Martin Feldstein, eds., Handbook of Public Economics, Vol. 4 of Handbook of Public Economics, Elsevier, 2002, pp. 1787-1872.

Hahn, Robert W., "An Economic Analysis of Scrappage," The RAND Journal of Economics, 1995, 26 (2), 222-242.

Hastings, Justine and Ebonya Washington, "The First of the Month Effect: Consumer Behavior and Store Responses," American Economic Journal: Economic Policy, May 2010, 2 (2), 142-162.

Kavalec, Chris and Winardi Setiawan, "An analysis of accelerated vehicle retirement programs using a discrete choice personal vehicle model," Transport Policy, 1997, 4 (2), 95-107.

Knittel, Christopher R., "The Implied Cost of Carbon Dioxide Under the Cash for Clunkers Program," 2009. Working Paper, Sloan School of Management, Massachusetts Institute of Technology.

Kotlikoff, Laurence J. and Lawrence H. Summers, "Tax Incidence," in Alan J. Auerbach and Martin Feldstein, eds., Handbook of Public Economics, Vol. 2 of Handbook of Public Economics, Elsevier, 1987, pp. 1043-1092.

Li, Shanjun, Joshua Linn, and Elisheba Spiller, "Evaluating 'Cash-forClunkers': Program Effect on Auto Sales, Jobs, and the Environment," 2010. Working Paper, Charles H. Dyson Scool of Applied Economics and Management, Cornell University.

Licandro, Omar and Antonio R. Sampayo, "The Effects of Replacement Schemes on Car Sales: The Spanish Case," Investigaciones Economicas, May 2006, 30 (2), 239-282.

Mazumder, Diya and Ruhai Wu, "Effects of Scrappage Subsidies in the Presence of Asymmetric Information," 2008. Working Paper, Department of Economics, Soka University of America. 
Mian, Atif and Amir Sufi, "The Effects of Fiscal Stimulus: Evidence from the 2009 Cash for Clunkers Program," Working Paper 16351, National Bureau of Economic Research September 2010.

Moretto, Michele, "Participation in Accelerated Vehicle Retirement Programs: An Option Value Model of the Scrappage Decision," International Journal of Transport Economics, 2000, 27 (1), 99-107.

Rothstein, Jesse, "Is the EITC as Good as an NIT? Conditional Cash Transfers and Tax Incidence.," American Economic Journal: Economic Policy, 2010, $2(1), 177-208$.

Sallee, James M., "The Surprising Incidence of Tax Credits for the Toyota Prius," American Economic Journal: Economic Policy, May 2011, 3 (2), 189 219 .

Sudhir, K., "Structural Analysis of Manufacturer Pricing in the Presence of a Strategic Retailer.," Marketing Science, 2001, 20 (3), 244-264.

Szwarcfiter, Lila, Francisco Eduardo Mendes, and Emilio Lebre La Rovere, "Enhancing the Effects of the Brazilian Program to Reduce Atmospheric Pollutant Emissions from Vehicles.," Transportation Research: Part D: Transport and Environment, 2005, 10 (2), 153-160.

Verboven, Frank, "Quality-Based Price Discrimination and Tax Incidence: Evidence from Gasoline and Diesel Cars.," The RAND Journal of Economics, 2002, 33 (2), 275-297. 